\title{
Review of fabrication methods of large-area transparent graphene electrodes for industry
}

\author{
Petri MUSTONEN (凶), David M. A. MACKENZIE, Harri LIPSANEN \\ Department of Electronics and Nanoengineering, Aalto University, Aalto FI-00076, Finland
}

(C) The Author(s) 2020. This article is published with open access at link.springer.com and journal.hep.com.cn

\begin{abstract}
Graphene is a two-dimensional material showing excellent properties for utilization in transparent electrodes; it has low sheet resistance, high optical transmission and is flexible. Whereas the most common transparent electrode material, tin-doped indium-oxide (ITO) is brittle, less transparent and expensive, which limit its compatibility in flexible electronics as well as in low-cost devices. Here we review two large-area fabrication methods for graphene based transparent electrodes for industry: liquid exfoliation and low-pressure chemical vapor deposition (CVD). We discuss the basic methodologies behind the technologies with an emphasis on optical and electrical properties of recent results. State-of-the-art methods for liquid exfoliation have as a figure of merit an electrical and optical conductivity ratio of 43.5 , slightly over the minimum required for industry of 35 , while CVD reaches as high as 419 .
\end{abstract}

Keywords transparent electrodes, graphene, liquid exfoliation, chemical vapor deposition (CVD)

\section{Introduction}

First observations of few-layer graphene was done by Novoselov et al. in 2004 when they isolated it from highly pyrolytic graphite [1] by mechanical exfoliation. Theoretical work by Peierls [2] and Landau [3] in the 1930s suggested that two-dimensional films are not stable, and their work was later further improved by Mermin in 1960s [4]. In 1980s, Nelson and Peliti showed that while twodimensional sheets are not stable, extending the sheet into the third dimension by buckling can make the film stable [5].

Graphene is a two-dimensional allotrope of carbon with a hexagonal lattice with multiple intriguing properties for

Received February 5, 2020; accepted June 5, 2020

E-mail: petri.mustonen@aalto.fi future electronics. It has a very long mean free path of charge carriers, in the order of tens of microns in low temperatures $(<130 \mathrm{~K})[6]$ and up to $1 \mu \mathrm{m}$ in roomtemperature [7], providing the possibility of devices using ballistic transport. It has a room-temperature electron mobility of $>10^{5} \mathrm{~cm}^{2} /(\mathrm{V} \cdot \mathrm{s})[8]$ and theoretical mobility of $2 \times 10^{6} \mathrm{~cm}^{2} /(\mathrm{V} \cdot \mathrm{s})$ [9]. Very high stiffness of up to $1 \mathrm{TPa}$ $[10,11]$ and intrinsic strength of $130 \mathrm{GPa}$ [12], but is still flexible due to its two-dimensionality. Monolayer graphene absorbs only $2.3 \%$ of light in the visible range, which is solely defined by the fine structure constant [13], and has a high thermal conductivity of $>3000 \mathrm{~m}^{-1} \cdot \mathrm{K}^{-1}$ [14] with a very good chemical stability [15-17]. It also exhibits interesting quantum mechanical phenomenon, such as, the breakdown on adiabatic Born-Oppenheimer approximation [18], room-temperature quantum Hall effect $[19,20]$, fractional quantum Hall effect [21] and a possibility of quantum anomalous Hall effect [22].

Unfortunately, many the aforementioned properties require extreme conditions or special, non-scalable, fabrication methods. Most of the graphene studied was derived from micromechanically exfoliated graphene, which is a non-scalable, low-yield and very mechanical process. Furthermore, in order to obtain these values, hexagonal boron nitride $(\mathrm{hBN})$ is used (or suspended graphene) as graphene substrate, which is also fabricated via micromechanical exfoliation.

Nowadays, the most common material for transparent electrodes is tin-doped indium-oxide (ITO). ITO has good optical transmission $(>90 \%)$ in the visible range and sheet resistances of $10-30 \Omega / \mathrm{sq}$ [23]. A significant downside to ITO is that indium is a rare-earth material, and hence, expensive. Generally, crystalline ITO is fabricated by magnetron sputtering on glass with a post-deposition hightemperature annealing process to initialize crystallization, which hinders the use of ITO on plastics [24]. Furthermore, ITO is prone to cracks at small bending radii [25] even if polycrystallinity is achieved [26,27].

This review will focus on chemical vapor deposition 
(CVD) and liquid exfoliation as fabrication methods for transparent graphene electrodes where sheet resistance $R_{\mathrm{S}}$ and optical transmission $T$ are main parameters in evaluation. A standard figure of merit, the ratio between electrical and optical conductivity, is calculated via

$$
\frac{\sigma_{\mathrm{DC}}}{\sigma_{\mathrm{OP}}}=\frac{Z_{0} \sqrt{T}}{2 R_{\mathrm{S}}(1-\sqrt{T})},
$$

where $\sigma_{\mathrm{DC}}$ and $\sigma_{\mathrm{OP}}$ are electrical and optical conductivity, $Z_{0}$ is the impedance of free space, $T$ is transmission and $R_{\mathrm{s}}$ is sheet resistance. While review articles on the field of two-dimensional materials (specifically graphene) are abundant, there are few that are written from an industrial viewpoint. Moreover, few of them adopt a specific figure of merit through which different methods are ranked. Here we remedy the situation by using a commonly applied figure of merit to a wide range of articles where the applied fabrication methods are potentially scalable to industrial needs as per authors' point of view.

Liquid exfoliation and CVD have been selected for this review due to the quality of the graphene produced, ease of use, throughput, and capabilities for large-area production and they both have been extensively studied. The methods complement one another, where CVD produces generally higher quality graphene, it also has higher capital costs and has more limited large-area capabilities. Liquid exfoliation deals with solvents (often aqueous) and therefore the area of produced graphene is not nearly as limited, it also enables easy integration to polymers and other materials as additives, enhancing their capabilities. Moreover, CVD often produces monolayers and it can be challenging to scale vertically, whereas achieving multilayers is easier in liquid exfoliation because the coating procedure is simpler than manually transferring multiple monolayers of graphene.

\section{Liquid exfoliation}

Exfoliation methods consist of two groups: liquid exfoliation and mechanical exfoliation. In mechanical exfoliation, a peeling force, commonly via an adhesive tape, separates graphitic layers from a dry graphite sample [28]. In comparison, liquid exfoliation uses vigorous agitation in a liquid resulting in separated graphitic layers in solution.

Liquid exfoliation is defined as the act of separating layers of material in a liquid solvent by exposing it to high shear forces. Liquid exfoliation takes advantage of the layered nature of graphite which has strong in-plane bonds but weaker van der Waals bonds out-of-plane that couple each layer. As a result, shearing forces can easily separate the layers down to individual monolayer sheets (graphene).

The most common method of liquid exfoliation is via agitation by sonication (see Fig. 1(a)), but there exist multiple different methods. Sonication creates highly energetic acoustic cavitation, where the resulting microbubbles produce pressures up to 500 atmospheres [29], hence providing more than enough shear force required for exfoliation [30]. Another agitation method is high-shear mixing, which involves a rotor-stator type of system, see Fig. 1(b). In this method, high shear-rates induce interlayer sliding of material, providing exfoliation [31].

There are several methods to increase exfoliation yield in agitation-based liquid exfoliation. The optimized choice of solvent is important because its function is to provide an environment where a stable dispersion of exfoliated material is possible. Organic solvents, such as, dimethylformamide (DMF) [34], N-methyl-2-pyrrolidone (NMP) [35], dichlorobenzene [36], and many others [37] fill these categories. Bunch et al. used liquid exfoliation in dichlorobenzene to produce few layer graphene flakes already in 2005 [36] but it was not until 3 years later when Hernandez et al. [35] were able to produce single layer graphene by using NMP, a solvent first introduced in liquid exfoliation carbon nanotubes [38], to produce graphene via sonication. Around this time, Coleman [39] investigated the reason why the aforementioned solvents are superior, and observed that well performing solvents have a surface tension of $\sim 40 \mathrm{~mJ} / \mathrm{m}^{2}$. An even better criterion for a good solvent is the Hildebrand solubility parameter, which should be close to $23 \mathrm{MPa}$. This was later shown by Hernandez et al. [37], who tested 40 different solvents for graphene. Unfortunately, many of these organic solvents possess high boiling points, making them hard to remove after dispersion [34,35,40-43].

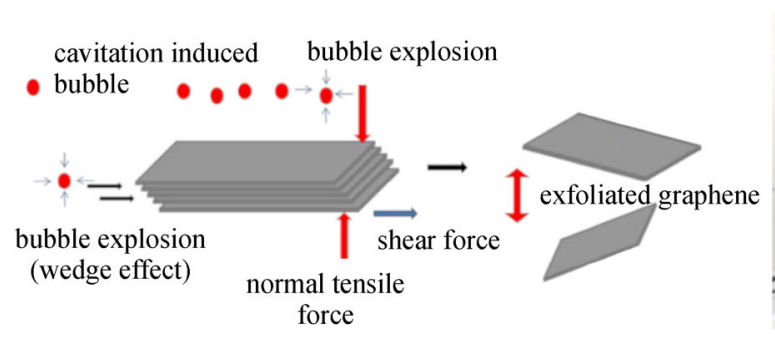

(a)

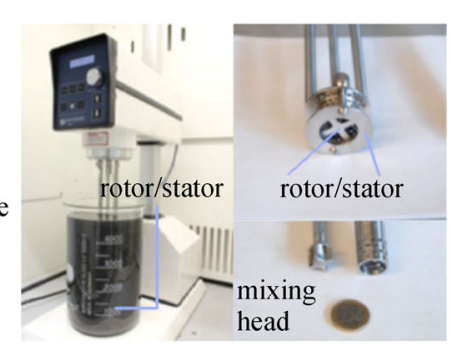

(b)

Fig. 1 (a) A possible route for cavitation-bubble induced liquid exfoliation of graphite to graphene. Adapted from Ref. [32]. (b) Highspeed shear mixing setup with a rotor, stator and mixing head visible. Adapted from Ref. [33] 
Another method to increase yield is to use surfactants to decrease the graphite interflake attraction. A surfactant method is desirable as it allows the utilization of solvents that are less toxic and have lower boiling points, e.g., water, methanol and isopropanol. There are multiple different surfactant types, such as ionic/non-ionic, aromatic/non-aromatic, polymers [44], that work by decreasing surface energy of graphite and therefore raising the number of usable liquid mediums. Disadvantages are that the residual surfactants are hard to remove and commonly deteriorate the electrical properties of graphene. A more indepth review of surfactant based liquid exfoliation is provided in Ref. [44].

Intercalation is a liquid exfoliation method where intercalating agents are used to increase the interlayer distance of graphitic layers, thereby decreasing the bond strength and making graphite easier to exfoliate. For instance, in electrochemical exfoliation, intercalants, such as ionic liquids [45], are used inside an electrochemical cell. A potential difference provides a charge to a graphite electrode, attracting intercalating species (cations or anions, depending on charge polarity) within the graphite sheets. The exfoliation happens through subsequent mechanical agitation or through spontaneous exfoliation via e.g., water splitting into oxygen/hydrogen gas due to an electrochemical reaction.

Low concentrations of graphene are problematic for fabricating continuous sheets for transparent electrodes because multiple depositions are needed to produce a percolating network, so it is important to have sufficient yield. Hernandez et al. [35] produced approximately $0.01 \mathrm{mg} / \mathrm{mL}$ of multilayer graphene $(<6$ layers $)$ with an approximate monolayer yield of $\sim 1 \mathrm{wt} . \%$ with relation to the original graphite mass. The achieved sheet resistance was $5.1 \mathrm{k} \Omega / \mathrm{sq}$ with $42 \%$ transmittance after a $250^{\circ} \mathrm{C}$ annealing in $\mathrm{Ar} / \mathrm{H}_{2}$ atmosphere. The concentration was further increased to $1.2 \mathrm{mg} / \mathrm{mL}$ [46] (or even up to $2 \mathrm{mg} / \mathrm{mL}$ [39]) by long-time sonication $(460 \mathrm{~h})$ and centrifugation where it was concluded that the ratio between monolayer-concentration and centrifugation time follows $\sqrt{t}$ behavior, whereas flake width and length follow $t^{-1 / 2}$, where $t$ is the centrifugation time.

Highly concentrated graphene solutions were prepared by Liang and Hersam, where ethyl cellulose (surfactant) enhanced ethanol was used as a solvent [40]. A $\sim 0.1 \mathrm{mg} / \mathrm{mL}$ concentration was achieved by few hour sonication and centrifugation; however, the concentration was increased by iterative solvent exchange to $1.02 \mathrm{mg} / \mathrm{mL}$. The corresponding sheet resistance was measured to be roughly $6 \mathrm{k} \Omega / \mathrm{sq}$ with optical transmittance of $\sim 70 \%$ at $550 \mathrm{~nm}\left(\sigma_{\mathrm{DC}} / \sigma_{\mathrm{OP}}=0.16\right.$, see Eq. (1)) after $400^{\circ} \mathrm{C}$ annealing. This method does not require hundreds or hours of sonication to acquire high-concentrations and does not use toxic NMP as a solvent. Recently, Li et al. used sonication with sodium citrate in NMP/water co- solvent to achieve few-layer graphene concentrations as high as $0.71 \mathrm{mg} / \mathrm{mL}$ with $4 \mathrm{~h}$ of sonication and $30 \mathrm{~min}$ of centrifugation [47]. Mean conductivity of annealed graphene $\left(500^{\circ} \mathrm{C}\right.$ for $2 \mathrm{~h}$ ) was $1.4 \times 10^{4} \mathrm{~S} / \mathrm{m}$, roughly twice that of the results by Hernandez et al. [35], with oxygen contents of $\sim 2.39 \%$. No transmittance or sheet resistance data was provided.

Unfortunately, removal of surfactants generally requires high-temperature annealing, and they introduce defects to the graphene structure due to them being electrically insulating [44]. In order to remedy the introduction of defects, Zhang et al. used pyrene-based surfactants (Py$\mathrm{NH}_{2}$ and $\mathrm{Py}-\mathrm{SO}_{3}$ ) [48] due to their ability to heal graphene defects during annealing [49]. It was reported that the initial sheet resistance (using Gr-Py- $\mathrm{NH}_{2}$ ) was $10^{8} \Omega / \mathrm{sq}$, which subsequently decreased to $10^{4} \Omega / \mathrm{sq}$ by $1000^{\circ} \mathrm{C}$ annealing. Better results were observed with $\mathrm{Py}-\mathrm{SO}_{3}$ surfactant, where the sheet resistance decreased down to $778 \Omega /$ sq. Both surfactants had transmittances of $\sim 90 \%$ $\left(\sigma_{\mathrm{DC}} / \sigma_{\mathrm{OP}}=4.5\right.$ and 0.35 for $\mathrm{Py}-\mathrm{SO}_{3}$ and $\mathrm{Py}-\mathrm{NH}_{2}$, respectively) on quartz substrates and with graphene concentrations of $\sim 0.4 \mathrm{mg} / \mathrm{mL}$. Transmittances of $\sim 40 \%$ were achieved on polydimethylsiloxane (PDMS) with sheet resistances of $10^{3} \Omega / \mathrm{sq}$. Again, high-temperature annealing is used to remove the adsorbed surfactants. An alternative method for circumventing this was applied by Tung et al., who used graphite oxides (GOs) as surfactants for pristine graphene [50] with the idea that the GOs only assist during exfoliation, after which they are removed by centrifugation and the graphene flakes are suspended in an appropriate solvent. The GOs are only attached non-covalently to graphene, hence they are easy to remove. Flakes with lateral dimensions of $5-10 \mu \mathrm{m}$ were achieved by this method and transparent electrodes on glass measured sheet resistance of $668 \Omega / \mathrm{sq}$ with transmittance of $80 \%\left(\sigma_{\mathrm{DC}} / \sigma_{\mathrm{OP}}\right.$ $=2.39$ ).

Another method for circumventing the long processing time of high-concentration graphene solutions by sonication is to use shear mixing instead of sonication. Furthermore, energy requirements for shear mixing scale better than sonication, which is of interest to industrialscale production. Paton et al. introduced this method and acquired sheet resistances of $10^{2} \Omega / \mathrm{sq}$, at sheet thicknesses of few hundred nanometers (no transmission data) [32]. Using this as a basis, Majee et al. were able to produce concentrated graphene ink $(3.2 \mathrm{mg} / \mathrm{mL})$ and use it in inkjet printing system to achieve sheet resistance of $\sim 260 \Omega / \mathrm{sq}$ at $85 \%$ transmittance after annealing in ambient at $350^{\circ} \mathrm{C}$, giving a figure of merit $\sigma_{\mathrm{DC}} / \sigma_{\mathrm{OP}}$ of 8.6 [51]. More recently, Shin et al. used high-shear mixing in a aqueous sodium cholate $(\mathrm{NaC})$ solvent with a direct transfer process based on the evaporation of isopropyl alcohol [52]. They were able to achieve flakes with average thickness of four layers $(50 \%$ of flakes less than four layers) with average lateral size of $\sim 110 \mathrm{~nm}$. The resulting 
sheet resistances were high, from $2 \times 10^{3}$ to $8 \times 10^{6} \Omega / \mathrm{sq}$ with transmittances of $44.5 \%$ to $73.1 \%$, respectively, resulting in figures of merit in between $\sim 0.25$ and $\sim 1.4 \times 10^{-4}$ without any annealing.

Methods other than based on mechanical agitation can be used as well to produce high-concentration graphene solutions through liquid exfoliation. In addition, agitationbased processing is inherently limited by mechanical properties (e.g., blade diameter, rotation speed, energy transfer) which can be avoided in some non-agitationbased methods. After the discovery of electrochemical functionalization of carbon nanotubes using ionic-liquids [53], Liu et al. introduced electrochemical exfoliation of graphite via ionic-liquids [45], however, the resulted sheets were quite small (lateral size $<1 \mu \mathrm{m}$ ). Su et al. later improved upon this by combining sulfuric acid, used in production of expanded graphite, and electrochemical exfoliation [54]. Multiple aqueous electrolytes $(\mathrm{HBr}, \mathrm{HCl}$, $\mathrm{HNO}_{3}$, and $\mathrm{H}_{2} \mathrm{SO}_{4}$ ) were tested in order to produce electrochemically exfoliated graphene. It was observed that $\mathrm{H}_{2} \mathrm{SO}_{4}$ produced the best results in mere minutes. All of the produced graphene flakes had thicknesses less than $3 \mathrm{~nm}$ (graphene interlayer distance was measured to be $0.45 \mathrm{~nm}$ and double-layer being $1.5 \mathrm{~nm}$ ) and lateral sizes of microns to tens of microns, with total yield of 5-8 wt.\% $(0.085 \mathrm{mg} / \mathrm{mL})$. By using interface aggregation method, thin films of $\sim 3.8 \mathrm{~nm}$ thickness were produced with transmittances of $\sim 96 \%$. The initial sheet resistance was $43 \mathrm{k} \Omega /$ sq which decreased to by $\mathrm{HNO}_{3}$ doping, and further decreased via $450^{\circ} \mathrm{C}$ annealing in $\mathrm{H}_{2} / \mathrm{Ar}$ atmosphere to $210 \Omega /$ sq, resulting in $\sigma_{\mathrm{DC}} / \sigma_{\mathrm{OP}}=13.9$ and 43.5 for nonannealed and annealed electrodes, respectively. Unfortunately, considerable amounts of defects were observed from Raman data, as a large disorder-peak is clearly visible.

Liu et al. further investigated electrochemical exfoliation by using aqueous solution of $\mathrm{Na}_{2} \mathrm{SO}_{4}$ with and without sonication assistance [55]. It was found out that the sonication further decreased the average flake thickness (from four to two layers) and number of defects considerably, increasing capacitor energy and power performances, but non-sonicated graphene showed better results for transparent electrodes. Non-sonicated graphene had a transmittance of $75.8 \%$ after $200^{\circ} \mathrm{C}$ annealing in air with $4.28 \mathrm{k} \Omega / \mathrm{sq}$ sheet resistance, which dropped drastically to $440 \Omega / \mathrm{sq}$ after $400^{\circ} \mathrm{C}$ annealing, corresponding to $\sigma_{\mathrm{DC}} / \sigma_{\mathrm{OP}}=2.88$, with oxygen contents of 16.3 and 13.0 at.\% for non-annealed and annealed samples (sonication had little effect in oxygen content). The number of defects from oxidation by intercalating ions is problematic as they decrease the quality of the acquired thin film. Parvez et al. were able to diminish this issue by using inorganic salts as an electrolyte for electrochemical exfoliation [56]. The most efficient electrolyte tested was $\left(\mathrm{NH}_{4}\right)_{2} \mathrm{SO}_{4}$, yielding graphene with much less oxygen content than the aforementioned Liu et al. [55], with a decrease from $\sim 13.0$ to 5.5 at.\%. The final result being a sheet resistance of $330 \Omega / \mathrm{sq}$ and a transmittance of $87 \%$ after doping with $\mathrm{HNO}_{3}$ and annealing at $300^{\circ} \mathrm{C}$, giving a figure of merit $\left(\sigma_{\mathrm{DC}} / \sigma_{\mathrm{OP}}\right)$ of 4.8 .

Recently, some new techniques have been developed for electrochemical exfoliation. Zhang and $\mathrm{Xu}$ achieved a significant yield increase (and production rate) by using a two metal-mesh wrapped graphite electrodes in a tetrabutylammonium perchlorate/polycarbonate (TBA $\mathrm{ClO}_{4} /$ PC) electrolyte, and utilizing both, cathodic and anodic exfoliation at the same time [57]. Yields of $85 \%$ and $48 \%$ and oxygen contents of approximately $4.7 \%$ and $5.4 \%$ were achieved for cathodic and anodic reactions, respectively, with $80 \%$ of flakes having thicknesses from one to three layers with a relatively small the Raman disorder peak $\left(I_{\mathrm{D}} / I_{\mathrm{G}}<0.08\right)$. Unfortunately, no transmittance data was measured and the only electrical measurements were conductivity measurements of graphene paper $\left(>3 \times 10^{4} \mathrm{~S} / \mathrm{m}\right)$ and sheet resistances of graphene ink $(10 \mathrm{mg} / \mathrm{mL})$ from $4 \mathrm{k} \Omega / \mathrm{sq}$ with one printing repetition down to $11 \Omega / \mathrm{sq}$ with six repetitions.

Another innovation was realized by Roscher et al., who used high-voltage cathodic exfoliation with boron-doped diamond electrodes to realize yields over $70 \%$ [58]. The electrolyte was tetrabutylammonium hexafluorophosphate/ polycarbonate ( $\mathrm{TBA} \mathrm{PF}_{6} / \mathrm{PC}$ ) and the specialized electrode was required to achieve the high potentials without the electrode dissolving. It was observed that the few-layer graphene yield increased substantially from $10 \%$ to over $70 \%$ when the applied voltage was increased from -30 to $-60 \mathrm{~V}$. Sheet resistances of $1.6-3.2 \mathrm{k} \Omega / \mathrm{sq}$ were measured at $\sim 70 \%$ transmittance (maximum $\sigma_{\mathrm{DC}} / \sigma_{\mathrm{OP}}=0.61$ ) after thermal annealing at $800^{\circ} \mathrm{C}$ with $I_{\mathrm{D}} / I_{\mathrm{G}}<0.2$, but with no data on oxygen contents. Highest figure of merit was achieved with $48 \%$ transmittance which had sheet resistance of $550 \Omega / \mathrm{sq}$, resulting in $\sigma_{\mathrm{DC}} / \sigma_{\mathrm{OP}}=0.78$.

The previous methods use cathodic or anodic reactions to force ions in between graphite sheets, thereby increasing the interlayer distance. This can also be done purely by chemical means, removing the complications that come from an electrochemical cell. Oxidizing graphite via Hummer's method is a common way of increasing the interlayer distance of graphite, which is discussed in more detail later in this work. Unfortunately, oxides introduce defects due to their insulating properties, which can be a problem with electrochemical exfoliation as well. In order to increase the interlayer distance of graphite without using oxides, Park et al. used ternary $\mathrm{KCl}-\mathrm{NaCl}-\mathrm{ZnCl}_{2}$ salts in a eutectic system to produce intercalation, separating graphene flakes in moderate temperatures of $\sim 300^{\circ} \mathrm{C}$ in $10 \mathrm{~h}$ [41]. Graphene yields of $\sim 60 \%$ were achieved (no mention of concentration) after a short (30 min) sonication. Sheet resistance of $\sim 930 \Omega / \mathrm{sq}$ with $\sim 75 \%$ transmittance (at $633 \mathrm{~nm}$ ), corresponding to $\sigma_{\mathrm{DC}} / \sigma_{\mathrm{OP}}=1.3$, were measured after $300^{\circ} \mathrm{C}$ annealing in hydrogen atmosphere and using modified Langmuir-Blodgett method, see Fig. 2(c), for 


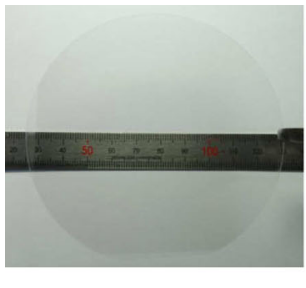

(a)

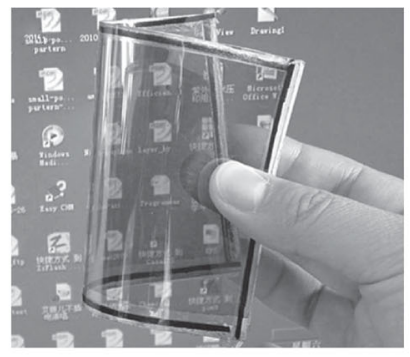

(b)

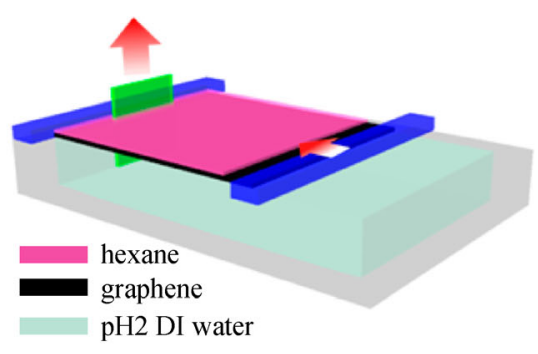

(c)

Fig. 2 (a) Reduced graphene oxide spray-coated on a 4-inch quartz wafer. Adapted from Ref. [66]. (b) Rod-coated room-temperature reduced graphene oxide transferred on a flexible PET substrate. Adapted from Ref. [69]. (c) Scheme for Langmuir-Blodgett method where a graphene film forms at the air-water-interface. The substrate is pulled upwards while the film is under steady compression. The film adheres to the substrate as it is pulled, and a monolayer transfer is achieved. Adapted from Ref. [41]

graphene coating. This type of chemical intercalation method is not limited by mechanical properties, merely the size of processing container, which makes it easier to scale.

Another source of graphene is from conversion of graphite to graphite oxide (GO). The conversion is commonly performed using Hummer's method (or modified Hummer's method) [59-61], but there exist multiple other methods as well [62]. The conversion relies on heavily oxidizing compounds, e.g., potassium permanganate $\left(\mathrm{KMnO}_{4}\right)$ and intercalants, such as sulfuric acid $\left(\mathrm{H}_{2} \mathrm{SO}_{4}\right)$. GO sheets are easier to exfoliate because the interlayer distance is already increased compared to graphite. In addition, GO is a stable suspension in a wider range of solvents (e.g., aqueous solvents) which is achieved due to the hydrophilic nature of the sheets. GO is intrinsically defective and electrically insulating due to surface oxides, which cannot be fully reversed via reduction [63], furthermore, reduction commonly uses high temperatures and toxic chemicals $[15,64-68]$, making it complicated and expensive.

Even though GO is inherently defective due to oxides, it is extremely easy to exfoliate, making it very commonly used material for producing graphene via liquid exfoliation. Whereas pristine graphene flakes produced by liquid exfoliation are generally hundreds of nanometers to few microns in lateral size, GO flakes can be up to $200 \mu \mathrm{m}$, as was shown by Zheng et al., who used intercalation based exfoliation with multiple consecutive centrifugations [15]. Reduction was done by annealing in $400^{\circ} \mathrm{C}$ and $1100^{\circ} \mathrm{C}$ subsequently. This produced films with sheet resistance of $\sim 600 \Omega /$ sq with $550 \mathrm{~nm}$ transmittance of $86 \%\left(\sigma_{\mathrm{DC}} / \sigma_{\mathrm{OP}}=\right.$ 4.01), which were improved via $\mathrm{HNO}_{3}(3 \mathrm{~h})$ and $\mathrm{SOCl}_{2}$ (24 h) doping to $459 \Omega / \mathrm{sq}, 90 \%$ and 7.59 for sheet resistance, transmittance and figure of merit $\left(\sigma_{\mathrm{DC}} / \sigma_{\mathrm{OP}}\right)$, respectively. The sheet resistance stabilized to $\sim 570 \Omega / \mathrm{sq}$ $\left(\sigma_{\mathrm{DC}} / \sigma_{\mathrm{OP}}=6.11\right)$ after four months.

A high-temperature reduction step has been investigated by Becerril et al. [68], who used thermal treatments of $400^{\circ} \mathrm{C}-1100^{\circ} \mathrm{C}$ and a combination of hydrazine vapor. It was observed that the best results are achieved via $1100^{\circ} \mathrm{C}$ thermal treatment (HT), but a combination of hydrazine vapor and low-temperature annealing at $400^{\circ} \mathrm{C}(\mathrm{H}-\mathrm{LT})$ is also utilizable due to the reduced temperatures. HT produced films with $\sim 4 \mathrm{k} \Omega / \mathrm{sq}$ sheet resistance at $\sim 82 \%$ transmission $(550 \mathrm{~nm})$ while H-LT resulted with sheet resistance of $\sim 40 \mathrm{k} \Omega / \mathrm{sq}$ and $\sim 78 \%$ transmission, giving figure of merits of 0.56 and 0.036 for HT and H-LT, respectively. Further improving on this, Wang et al. used cellulous ester filter membranes with vacuum filtering and combined the hydrazine, low-temperature annealing $\left(400^{\circ} \mathrm{C}\right)$ and high-temperature annealing $\left(1100^{\circ} \mathrm{C}\right)(\mathrm{H}-$ LT-HT) [64]. H-LT transmittance was $\sim 87 \%$ with sheet resistance of $\sim 50 \mathrm{k} \Omega / \mathrm{sq}\left(\sigma_{\mathrm{DC}} / \sigma_{\mathrm{OP}}=0.05\right)$ or $\sim 60 \%$ and $\sim 6$ $\mathrm{k} \Omega / \mathrm{sq} \quad\left(\sigma_{\mathrm{DC}} / \sigma_{\mathrm{OP}}=0.11\right)$. The combination (H-LT-HT) resulted in much better properties of $\sim 74 \%$ transmittance and $2 \mathrm{k} \Omega / \mathrm{sq}$ sheet resistance $\left(\sigma_{\mathrm{DC}} / \sigma_{\mathrm{OP}}=0.58\right)$.

The high temperatures required for the reduction of GO are problematic for flexible electrodes based on polymer substrates due to their low melting points, and because it increases fabrication costs. In order to decrease the reduction temperature, Pham et al. mixed graphite oxide with hydrazine monohydrate and spray-deposited this mixture on pre-heated quartz substrates [66] instead of using hydrazine vapor and high-temperature annealing after deposition for reduction. It was reported that a considerable reduction happened already at temperatures of $240^{\circ} \mathrm{C}$ with a final sheet resistance of $2.2 \mathrm{k} \Omega / \mathrm{sq}$ with transmittance of $84 \%\left(\sigma_{\mathrm{DC}} / \sigma_{\mathrm{OP}}=0.94\right)$, see Fig. 2(a). Even lower reduction temperatures were achieved by Wang et al. [69], who used room-temperature reduction in hydrogen atmosphere with a palladium catalyst. Small amounts of palladium chloride $\left(\mathrm{PdCl}_{2}\right)$ was added into the $\mathrm{GO}$ solution before rod-coating and drying a polyethylene terephthalate (PET) substrate in ambient air, see Fig. 2(b). GO was reduced in hydrogen atmosphere in ambient temperature for $6 \mathrm{~h}$. A thin film with a sheet resistance of $1.68 \mathrm{k} \Omega / \mathrm{sq}$ was achieved with transmittance of $64.6 \%\left(\sigma_{\mathrm{DC}} / \sigma_{\mathrm{OP}}=\right.$ $0.46)$. Alahbakhski et al. were able to come close to that of the aforementioned Wang et al. results by combining chemical reduction by hydroionic acid (HI) and a 
subsequent lower temperature thermal treatment $\left(700^{\circ} \mathrm{C}\right)$ [67]. They achieved sheet resistance of $1.1 \mathrm{k} \Omega / \mathrm{sq}$ with $89 \%$ transmittance $\left(\sigma_{\mathrm{DC}} / \sigma_{\mathrm{OP}}=2.86\right)$ using chemical reduction with the thermal treatment; and using only chemical reduction, sheet resistance and transmittance of $1.7 \mathrm{k} \Omega / \mathrm{sq}$, and $75 \%\left(\sigma_{\mathrm{DC}} / \sigma_{\mathrm{OP}}=0.72\right)$ were achieved, respectively. Table 1 includes a collection of all the discussed results, as well as multiple others. The best results for the figure of merit are 45.5 and 13.9 via electrochemical exfoliation; however, most of the obtained values do not reach the minimum required values for industry $\left(\sigma_{\mathrm{DC}} / \sigma_{\mathrm{OP}}=35\right)$ $[70]^{1)}$. It is worth noting that very few of the discussed liquid exfoliation methods used any kind of doping.
Doping can potentially double, or triple, the figure of merits, after which the electrochemical methods could reach values above 100 . More details on graphene doping are presented in the next section.

\section{Chemical vapor deposition}

CVD is a process of depositing a compound in a controllable fashion on surfaces via thermal and catalytic decomposition of precursors. This initiates a chemical reaction between the decomposed products and a substrate in order to produce a desired result. The result can be, for

Table 1 Summary of liquid exfoliated graphene based transparent electrodes, where $R_{\mathrm{s}}, T$, and $\sigma_{\mathrm{DC}} / \sigma_{\mathrm{OP}}$ refer to sheet resistance, transmittance (at $550 \mathrm{~nm}$ ) and figure of merit, respectively. Annealing column mentions whether high-temperature annealing is done and at what temperature. Exfoliation method explains which method is used and whether surfactants are used; if only GO is mentioned, then no agitation is used for exfoliation

\begin{tabular}{|c|c|c|c|c|c|}
\hline$R_{\mathrm{S}} /\left(\Omega \cdot \mathrm{sq}^{-1}\right)$ & $T / \%$ & $\sigma_{\mathrm{DC}} / \sigma_{\mathrm{OP}}$ & annealing $/{ }^{\circ} \mathrm{C}$ & exfoliation method & Ref. \\
\hline 100 & 90 & 35 & - & - & minimum industry requirement [70] \\
\hline 22500 & 62 & 0.03 & 250 & surfactant + sonication & [71] \\
\hline 40000 & 78 & 0.036 & $400^{\mathrm{a})}$ & $\mathrm{GO}+$ sonication & [68] \\
\hline 5100 & 42 & 0.069 & 250 & sonication & {$[35]$} \\
\hline 6000 & 60 & 0.11 & $400^{\mathrm{a})}$ & $\mathrm{GO}+$ sonication & {$[64]$} \\
\hline 6000 & 70 & 0.16 & - & surfactant + sonication & {$[40]$} \\
\hline 1500 & 44 & 0.25 & - & shear & {$[52]$} \\
\hline 3200 & 70 & 0.30 & 600 & electrochemical & [58] \\
\hline 4000 & 76 & 0.32 & 500 & surfactant + sonication & [72] \\
\hline 5000 & 80 & 0.32 & 800 & surfactant $+\mathrm{GO}+$ sonication & {$[65]$} \\
\hline 1000 & 47 & 0.41 & 500 & surfactant + sonication & [72] \\
\hline 1680 & 65 & 0.46 & - & $\mathrm{GO}+$ sonication & [69] \\
\hline 4000 & 82 & 0.56 & 1100 & $\mathrm{GO}+$ sonication & [68] \\
\hline 2000 & 74 & 0.58 & $400+1100^{a)}$ & $\mathrm{GO}+$ sonication & [64] \\
\hline 550 & 48 & 0.78 & 600 & electrochemical & [58] \\
\hline 1700 & 75 & 0.72 & - & GO & [67] \\
\hline 2200 & 84 & 0.94 & 1100 & $\mathrm{GO}+$ sonication & [66] \\
\hline 930 & 75 & 1.3 & 300 & intercalation & [41] \\
\hline 668 & 80 & 2.39 & 350 & surfactant + sonication & {$[50]$} \\
\hline 1100 & 89 & 2.86 & 700 & GO & [67] \\
\hline 440 & 76 & 2.9 & 400 & electrochemical & {$[55]$} \\
\hline 600 & 86 & 4.01 & $400+1100$ & intercalation $+\mathrm{GO}$ & [15] \\
\hline 778 & 90 & 4.5 & 1000 & surfactant + sonication & [48] \\
\hline 330 & 87 & 4.8 & 300 & electrochemical & {$[56]$} \\
\hline 459 & 90 & 7.59 & $400+1100^{b)}$ & intercalation $+\mathrm{GO}$ & [15] \\
\hline 260 & 85 & 8.6 & 350 & shear & [43] \\
\hline 657 & 96 & 13.9 & 450 & electrochemical & [54] \\
\hline $210^{\text {a) }}$ & 96 & 43.5 & 450 & electrochemical & [54] \\
\hline
\end{tabular}

Notes: a) Hydrazine vapor + annealing. b) Chemical doping via $\mathrm{HNO}_{3}$ and $\mathrm{SOCl}_{2}$.

1) The authors of the reference were collaborating with Hewlett Packard (HP) in development of transparent electrodes and HP specified that the minimum required values for industry are $100 \Omega /$ sq with $90 \%$ transmittance. 
example, a molecular coating with a specific crystal structure or a complex compound agglomerates on predetermined nucleation sites.

There are commonly four different terms that are used in describing CVD equipment: hot wall, cold wall, horizontal geometry and vertical geometry. In a hot wall reactor, the substrate is heated by heating the reactor walls. Here the reaction zone, the area where chemical reactions take place, is large. Whereas in a cold wall reactor, the substrate is heated directly, and the chemical reactions take place only on the substrate. Horizontal geometry is the most common one, which is a horizontal quartz tube with heating elements surrounding it in the middle. Here precursor and carrier gases flow laterally over the sample, through the reaction zone, see Fig. 3(a). In a vertical geometry, the gases flow vertically towards the substrate. Usually horizontal furnaces are hot wall furnaces and vertical furnaces are cold wall. Pressure also differentiates CVD equipment; low- and atmospheric pressure CVD are the most common, but ultra-high vacuum and highpressure CVDs are also an option.

Commonly in CVD of graphene, a catalytic substrate (generally a transition metal [73]), such as copper or nickel, is heated to $\sim 1000^{\circ} \mathrm{C}$ under hydrogen $\left(\mathrm{H}_{2}\right)$ and argon (Ar) flow in a low-pressure $\left(10^{-3}-10^{-2} \text { bar }\right)^{1)}$ system. Afterwards, a hydrocarbon precursor is introduced into the system and it goes through a catalytic dehydrogenation due to the elevated temperatures.

A common hydrocarbon source is methane $\left(\mathrm{CH}_{4}\right)$ because its stability allows higher temperatures, hence provoking higher quality graphene growth. Other gas phase hydrocarbons, such as acetylene $\left(\mathrm{C}_{2} \mathrm{H}_{2}\right)$ and ethylene $\left(\mathrm{C}_{2} \mathrm{H}_{4}\right)$, can be used at lower temperatures $\left(600^{\circ} \mathrm{C}-800^{\circ} \mathrm{C}[74,75]\right.$ and $800^{\circ} \mathrm{C}-900^{\circ} \mathrm{C}[76-78]$, respectively). Graphene can be grown via multiple other hydrocarbon sources, such as polymethyl methacrylate (PMMA), sucrose, fructose [79], silicon carbide via sublimation [80], propane and ethane [81] and polycyclic aromatic hydrocarbons [82]. In the end, multiple different routes for graphene CVD exist: plasma enhanced CVD (PECVD), using different hydrocarbons, atmospheric pressure CVD, ultra-low pressure, deposition on insulating surfaces and many others. A very throughout review of these methods as well as more in-depth discussion of transfer methods and growth on multiple substrates can be found in Ref. [83].

In the case of copper and methane, the hydrocarbon adsorbs on the substrate and go through a series of dehydrogenation steps: $\mathrm{CH}_{4}(\mathrm{~g}) \rightarrow \mathrm{CH}_{4}(\mathrm{~s}) \rightarrow \mathrm{CH}_{3}(\mathrm{~s})+$ $\mathrm{H}(\mathrm{s}) \rightarrow \mathrm{CH}_{2}(\mathrm{~s})+2 \mathrm{H}(\mathrm{s}) \rightarrow \mathrm{CH}(\mathrm{s})+3 \mathrm{H} \rightarrow \mathrm{C}(\mathrm{s})+4 \mathrm{H}(\mathrm{s})$, where (s) and (g) represent solid (adsorbed) and gaseous phases. Here, the rate-limiting step is the last step of $\mathrm{CH}(\mathrm{s})+3 \mathrm{H}(\mathrm{s}) \rightarrow \mathrm{C}(\mathrm{s})+4 \mathrm{H}(\mathrm{s})$ with an activation energy of $1.5-1.9 \mathrm{eV}[73,85]$. However, experimentally the entire graphene growth process: adsorption, dissociation, diffusion and growth (see Fig. 3(b)) has an energy barrier of $1.5-3.1 \mathrm{eV}$ [86-89], suggesting that nucleation is the final rate-limiting step, as analyzed by Shu et al. [90]. It was argued that the energy barrier for carbon incorporation process can be as high as $\sim 2.5 \mathrm{eV}$ for $\mathrm{Cu}(110)$ but it can be lowered down to $0.8 \mathrm{eV}$ by using $\mathrm{Cu}(111)$, even though Kim et al. did not observe this experimentally [86]. More complications arise from the fact that the methane dissociation is not straightforward $\mathrm{CH}_{4}(\mathrm{~g}) \rightarrow \mathrm{CH}_{4}(\mathrm{~s}) \rightarrow$ $\mathrm{CH}_{3}(\mathrm{~s})+\mathrm{H}(\mathrm{s}) \rightarrow \mathrm{CH}_{2}(\mathrm{~s})+2 \mathrm{H}(\mathrm{s}) \rightarrow \mathrm{CH}(\mathrm{s})+3 \mathrm{H} \rightarrow \mathrm{C}(\mathrm{s})+$ $4 \mathrm{H}(\mathrm{s})$, but intermediate compounds, such as acetylene $\left(\mathrm{C}_{2} \mathrm{H}_{2}\right)$, ethylene $\left(\mathrm{C}_{2} \mathrm{H}_{4}\right)$, and ethane $\left(\mathrm{C}_{2} \mathrm{H}_{6}\right)$, are formed on the copper substrate as well $[84,91]$.

The hydrocarbon dissociation energy and the substrate's catalytic power define the growth temperature. Dehydrogenation energy is different for each carbon source, e.g., dissociation energy of $\mathrm{CH}_{3}-\mathrm{H}$ (first dehydrogenation step of $\mathrm{CH}_{4}$ ) is $4.85 \mathrm{eV}$ in gas phase [92], (it is the most stable hydrocarbon up to $\sim 1000^{\circ} \mathrm{C}$ [93]) but can be reduced to $<1 \mathrm{eV}$, on substrates such as Pt [94], Ru, Os, Rh, Ir and $\mathrm{Pd}$, whereas for $\mathrm{Cu}$ it is slightly higher of $1.12 \mathrm{eV}$ [73].

The dissociated hydrocarbon species diffuse on the substrate until the concentration of active carbon species is high enough to initiate nucleation. The nucleation spots grow outwards until they coalesce with other nucleation spots and cover the entire surface $[95,96]$. This deliberate catalyst poisoning will stop the surface catalytic reactions

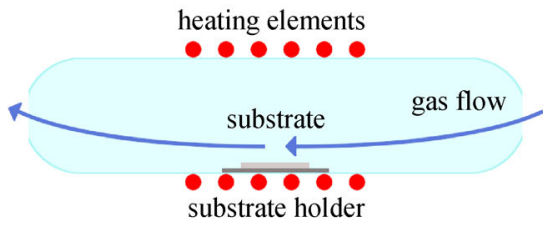

(a)

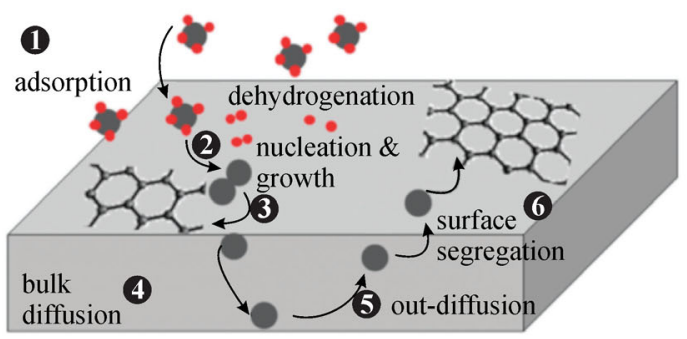

(b)

Fig. 3 (a) Schematic picture of a horizontal quartz furnace where gases flow laterally over the substrate in a reaction zone surrounded by heating elements. (b) Simplified scheme of graphene growth in CVD. Hydrocarbons adsorb on the surface (1), dehydrogenate (2), nucleate and grow (3), diffuse to bulk if high carbon soluble substrate (4), diffuse out (5), and segregate (6). Adapted from Ref. [84]

1) $1 \mathrm{bar}=10^{5} \mathrm{~Pa}$. 
from taking place as the copper surface is no longer exposed to the hydrocarbons and therefore the catalytic decomposition stops. Surface catalytic growth is a common term for this growth mechanism and it takes place in low solubility transition metals, such as copper ( 7.4 at.ppm) [97].

In contrast, some transition metals have a high carbon solubility, such as nickel (1.5 at.\%) [98,99], and the growth mechanism behind these substrates is called precipitation growth. In precipitation growth, the active carbon species absorb into the bulk of the substrate, and precipitate back to the surface when the substrate cools, see Fig. 3(b). After precipitation, the carbon species diffuse and nucleate, forming graphene [100]. Achieving monolayer growth via precipitation method is difficult because there are no mechanisms that stop subsequent layers from growing under the initial graphene layer. This method also introduces the rate of cool down as an important optimization parameter. Even though the aforementioned process is a common explanation of the precipitation mechanism, there exist nuances to it, such as that the amount of surface catalytic growth is still crucial for highquality graphene growth [101], and that the active carbon species inside the bulk already form carbon chains and irregular carbon clusters prior to surface nucleation [102].

One of the first CVDs of multilayer-graphene was done by Kim et al. [98] using thin $(300 \mathrm{~nm})$ nickel layer on $\mathrm{SiO}_{2}$ and methane as the hydrocarbon precursor. Two different graphene transfer methods were introduced: PDMS stamping and $\mathrm{SiO}_{2}$ etching method. In the former method, a PDMS stamp is pressed on the graphene/nickel stack and the nickel layer is etched away in $\mathrm{FeCl}_{3}$, then the PDMS/ graphene stack is pressed on an arbitrary substrate and the PDMS is peeled off. $\mathrm{SiO}_{2}$ method involves etching the oxide layer in hydrogen fluoride (HF) solution, leaving the nickel/graphene stack intact. Afterwards the stack is scooped off from the solution on an arbitrary substrate and the nickel layer can be removed with $\mathrm{FeCl}_{3}$. The results were sheet resistance of with $76 \%$ transmittance at $550 \mathrm{~nm}\left(\sigma_{\mathrm{DC}} / \sigma_{\mathrm{OP}}=4.6\right)$.

However, the PDMS stamping method is a very manual technique only suitable for small samples. In order to remedy this, Verma et al. developed a quick and easy largescale graphene transfer technique to flexible PET substrates [103]. Graphene synthesized on copper foil via CVD was transferred to PET by hot press lamination, where the copper/graphene stack is merely fed through an office laminator, which adheres a PET film on top of the graphene layer. Afterwards the copper layer was removed in $\mathrm{FeCl}_{3}$ and graphene on a flexible PET substrate is achieved. Foldability was gauged via measuring the resistance as a function of the bending radii and it was found out that the resistance increase is only $\sim 20 \%$ and it recovers completely after unbending. Measured sheet resistance was $1174 \Omega / \mathrm{sq}$ with transmittance of $88.8 \%\left(\sigma_{\mathrm{DC}} / \sigma_{\mathrm{OP}}=2.62\right)$.

Another way to circumvent issues with the transfer process is to directly grow graphene on an insulating surface. Kalita et al. grew graphene directly on quartz by utilizing camphor as the hydrocarbon source [104]. A horizontal furnace with two heating elements was used. First element was kept at $200^{\circ} \mathrm{C}$ and was used to evaporate the camphor and the second element provided gas-phase pyrolysis at $800^{\circ} \mathrm{C}-900^{\circ} \mathrm{C}$, where the quartz substrates were placed. A highly defective few-layer graphene was grown with sheet resistance of $1.645 \mathrm{k} \Omega / \mathrm{sq}$ and transmittance of $81 \%$ at $550 \mathrm{~nm}$.

A way to increase the productivity of a standard horizontal furnace was investigated by Nagai et al., where a high-reactivity hydrocarbon source, acetylene $\left(\mathrm{H}_{2} \mathrm{C}_{2}\right)$, was used instead of the more stable methane $\left(\mathrm{CH}_{4}\right)$ [105]. Multiple rolled copper foils were placed inside one another in a horizontal hot-wall furnace and graphene was grown in less than $20 \mathrm{~min}$ (15 min heating, 1 min annealing and $1.5 \mathrm{~min}$ growth) in $975^{\circ} \mathrm{C}$. The method produced 1-2 layers of graphene with sheet resistances of 780-1680 $\Omega / \mathrm{sq}$ and transmittances of $94.8 \%-96.7 \%\left(\sigma_{\mathrm{DC}} / \sigma_{\mathrm{OP}}=\right.$ 4.76-11.45). The sheet resistances decreased down to $299 \Omega / \mathrm{sq}$ after p-doping with $\mathrm{HNO}_{3}$ vapors with only $0.2 \%$ transmittance increase, giving a figure of merit of 28.4 .

Another method for increasing productivity is to use a roll-to-roll production instead of a batch production. Rollto-roll production has the capabilities of fabricating graphene in very large quantities in a continuous manner. Bae et al. used an 8-inch wide horizontal furnace with a 7.5-inch suspended quartz tube wrapped with copper foil to realize very large-area graphene production [106]. Afterwards the copper/graphene stack was adhered to thermal release tape in between two rollers, and finally the copper layer is etched in ammonium persulfate solution. The graphene can be transferred from the thermal release tape to any substrate by exposing it to mild temperatures of $90^{\circ} \mathrm{C}-120^{\circ} \mathrm{C}$. A four-layer graphene electrode on PET substrate with $\mathrm{HNO}_{3}$ doping has a sheet resistance of $30 \Omega /$ sq with $90 \%$ transmittance. Single-layer graphene shows values of $\sim 110 \Omega / \mathrm{sq}$ and $97.4 \%$ for sheet resistance and transmittance, respectively. These values result in figures of merits of 116 and 135, respectively.

Graphene is often transferred on flexible polymers in order to produce flexible transparent electrodes. Previously mentioned polymers, PET and PDMS, are common choices for this. Kim et al. used ionic liquid based cellulose as a flexible polymer for graphene based $\mathrm{NO}_{2}$ sensors due to it having chemical properties that enable sensitive and selective gas sensing [107]. Cellulose is also an eco-friendly substrate with good thermal and chemical stabilities, and excellent solubility. The effect of cellulose on the graphene defect density was observed to be small due to the smaller sheet resistance of graphene/cellulose film in comparison to graphene $/ \mathrm{SiO}_{2}$ film; Raman disorder peak (d-peak) could not be used in this effect because the cellulose peak is superimposed on the graphene disorder 
peak. The fabricated film had a sheet resistance of $320 \Omega / \mathrm{sq}$ with transmittance of $98 \%$ at $550 \mathrm{~nm}$, resulting with $\sigma_{\mathrm{DC}} / \sigma_{\mathrm{OP}}=58.02$.

Another less common polymer, CVD parylene, has been used as a supporting polymer for flexible electrodes by Kim et al. [108]. Copper foil was removed from parylene/ graphene/copper stack via bubbling transfer method, where hydrogen bubbles peel away the copper foil from graphene in an electrochemical $(\mathrm{NaOH})$ solution. The pristine graphene sheet resistance of $150 \Omega /$ sq was reduced to 100,30 and $20 \Omega$ /sq with $\mathrm{Kl}, \mathrm{AuCl}_{3}$ and $\mathrm{HNO}_{3}$ dopants with transmission of $\sim 96.5 \%$. This led to extremely high figure of merit values of $\sim 420$.

Even though the previously mentioned results focus on the transfer process or substrates, the growth process itself is not perfect and it introduces defects as well, such as grain boundaries due to the polycrystalline nature of the growth process. To reduce the effects of grain boundaries, pin-holes and cracks, Park et al. applied an interesting defect healing technique, where gold nanoparticles were selectively transferred to defective sites via electroplating [109]. The charge distribution of graphene is dependent on its defect distribution; therefore, current densities within the gold chloride $\left(\mathrm{AuCl}_{3}\right)$ electroplating solution change near defects, allowing selective transfer of gold nanoparticles to defected areas. This is shown schematically in Fig. 4. The transferred nanoparticles were capped by mechanically transferring a second graphene layer on top of the nanoparticles. The capping layer was found to be important, as the increase of sheet resistance (roughly three orders of magnitude) without it was nearly identical to that of pristine graphene under accelerated conditions (temperature at $85^{\circ} \mathrm{C}$ and humidity at $85 \%$ ). With the capping layer, the increase was from three-fold to ten-fold, depending on the number of transferred (and doped) layers. The importance of capping layers was also shown in the case of bending strain, where samples with capping layers shows only two- to three-fold increase in sheet resistance $(0.58 \%-9.4 \%$ strain), whereas without capping layers the increase is $>46$-fold at $\sim 5 \%$ strain. The selectively transferred nanoparticles also increase the

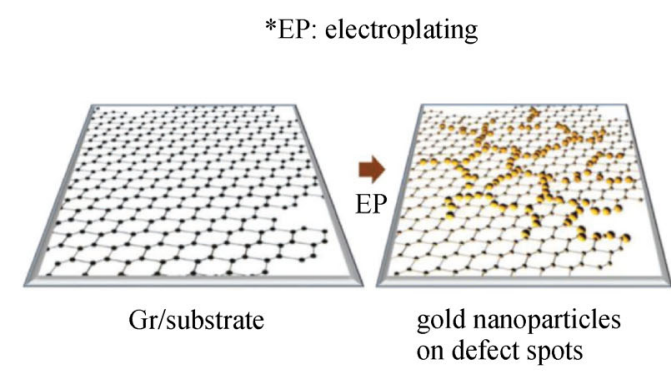

(a) uniformity of sheet resistance, as is seen from the decrease of standard deviation from 54.89 to $12.73 \Omega / \mathrm{sq}$. In the end, best figure of merit was 42.5 when using one graphene layer without capping and with three, and five-layers of graphene (and doping) figure of merit decreased to 29.9 and 31.1 , respectively.

The standard wet transfer process for graphene uses a supporting polymer layer on top of the graphene, which allows the etching or delamination of the polymer/ graphene layers from the growth substrate. The supportive polymer is normally dissolved away after the transfer process. This technique commonly introduces folds and cracks on the graphene due to its non-rigid supportive polymer layer (commonly a thin layer of PMMA), and due to DI-water getting trapped in between the supportive polymer and the target substrate, even after drying. The folds and cracks can be reduced by using a more complex version of the transfer, where the target substrate is e.g., RCA (Radio Corporation of America) cleaned and HF dipped to increase hydrophobicity [110], or by a double PMMA deposition [111]. The use of PMMA as a supportive polymer also introduces residues on the graphene surface, which have been shown to affect transport properties [112]. The amount of residues can be reduced, for example, by using ultra-high vacuum annealing or annealing in $\mathrm{H}_{2} / \mathrm{Ar}$ atmosphere $[113,114]$, or by using a different supporting layer $[115,116]$. However, this process is easy to use and does not require any specialized equipment, making it a very common transfer technique. Furthermore, the supporting polymer makes a conformal contact with the graphene, reducing the number of holes in it after transfer to rigid substrates. Unfortunately, it is a very mechanical process and does not have a high throughput nor is it compatible with large-area processing. Also, while this method can be used for transferring graphene on arbitrary substrates, it is difficult to achieve a conformal transfer on non-rigid substrates [117].

Stamping method on the other hand is a dry-transfer (or semi-dry) method, minimizing polymer residues by skipping the polymer dissolving step entirely, opting for

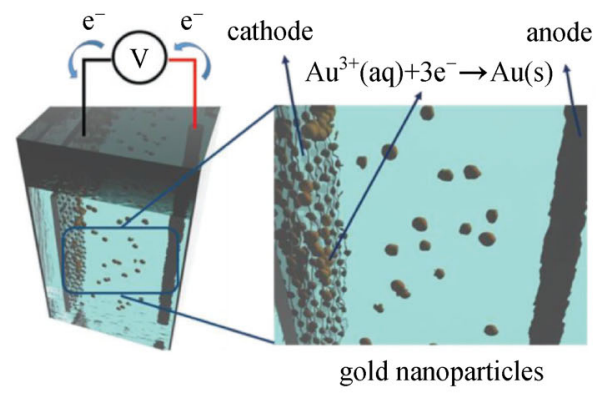

(b)

Fig. 4 Defect healing scheme by Park et al., where gold nanoparticles are electroplated onto defected areas, increasing their conductivity. Adapted from Ref. [109]. (a) Schematic figure on where the gold nanoparticles coalesce after electroplating process. (b) Electroplating scheme of the gold nanoparticles 
a mechanical removal process instead. PDMS is commonly used as the supportive layer and the increased rigidity of it in comparison to PMMA decreases the amount of folds and creases in the transferred graphene layer. The downsides being that the graphene layer can break because the PDMS is mechanically peeled away, and it is still not a residue-free process [118]. Also, this transfer method is not universal because it requires the adhesion force between graphene and the target substrate to be larger than in between graphene and PDMS. Furthermore, the target substrate should be rigid and clean in order to achieve a good conformal transfer. A modified version of this involves a secondary release layer in between the stamp and the graphene [118-120], allowing the transfer to a wider range of substrates.

Hot press lamination is a method, where the graphene is transferred directly from the growth substrate to the final substrate utilizing an adhesive layer that is melted and solidified by various means [103,106,117,121-123]. A similar method in comparison to the stamping method, but it usually utilizes higher temperatures and requires a separate machine for the transfer process. This process can be high-throughput and is applicable to large-area transfer if a roll-to-roll processing is applied, allowing transfer with minimal manual work. It is also compatible with growth substrate etching and electrochemical delamination, and can be used with a self-release layer, allowing full drytransfer [122]. However, this method can introduce voids and cracks in the graphene layer, possibly due to the nonconformality of the mechanical pressing (hot press or lamination between rollers) $[124,125]$.

Electrochemical delamination is a version of the standard wet transfer where the growth substrate is not etched away, but instead, it is delaminated in an electrochemical cell. This method retains the growth substrate thereby substantially increasing the economy and ecology of the transfer process as the growth substrate can be re-used multiple times, potentially increasing the graphene quality in subsequent growth runs [126-128]. The original electrochemical delamination technique used $\mathrm{H}_{2}$ bubbles to slowly peel the polymer/graphene layer from the growth substrate [127], but this easily introduces voids and cracks on the graphene due to vigorous hydrogen evolution, and due to $\mathrm{H}_{2} \mathrm{O}$ permeating through the supporting polymer layer [129]. Second method is to use electrochemistry to reduce a copper oxide layer beneath the graphene, lowering the graphene adhesion enough that it readily peels off via surface tension $[126,128]$. Unfortunately, these electrochemical techniques need even more manual work than the standard etching method. Though it does have the potential for high-throughput processing due to its fast delamination (minutes instead of hours), but if the oxide reduction technique is used then the surface beneath graphene must be oxidized prior to transfer.

Graphene can also be grown using PECVD, where the growth temperatures can be lowered substantially by lowering the energy barrier for hydrocarbon pyrolysis and dissociation. It can also be utilized for growing graphene on insulating substrates [130-133], skipping entirely the transfer process. Recently, PECVD has been used in conjunction with copper foam by Wei et al. to grow graphene on flexible glass [134]. This allows lower growth temperatures and the copper foam shielding the graphene from ion bombardment and smoothening the electric field. A RF plasma power of $80 \mathrm{~W}$ was used in $\mathrm{Ar} / \mathrm{H}_{2} / \mathrm{CH}_{4}$ atmosphere in pressures of $2 \mathrm{~Pa}$ at low growth temperatures of $500^{\circ} \mathrm{C}-750^{\circ} \mathrm{C}$. The grown graphene had transmittances between $68.5 \%$ and $89.5 \%$ and sheet resistances of $1.38-5.15 \mathrm{k} \Omega / \mathrm{sq}$, respectively, with the best figure of merit being $\sigma_{\mathrm{DC}} / \sigma_{\mathrm{OP}}=0.66$.

In comparison to this, Chen et al. used RF plasma powers of $150 \mathrm{~W}$ at $600^{\circ} \mathrm{C}$ with glass substrates in $\mathrm{Ar} / \mathrm{H}_{2} /$ $\mathrm{CH}_{4}$ atmosphere at pressures of $50 \mathrm{~Pa}$ [135]. The result was a graphene sheet with transmittance of $83.7 \%$ and sheet resistance of $661 \Omega / \mathrm{sq}$, giving a figure of merit of $\sigma_{\mathrm{DC}} / \sigma_{\mathrm{OP}}$ $=3.09$.

A different approach was used by Vishwakarma et al. who realized $\mathrm{CO}_{2}$ and $\mathrm{O}_{3}$ enhanced PECVD graphene at low stage temperatures of $300^{\circ} \mathrm{C}$ using $1000 \mathrm{~W}$ microwave plasma in $\mathrm{Ar} / \mathrm{H}_{2} / \mathrm{CH}_{4}$ atmosphere [136]. Low amounts of $\mathrm{CO}_{2}(0.3 \mathrm{sccm})$ decreased sheet resistance of the graphene while only slightly decreasing transmittance, while $\mathrm{O}_{3}$ improved both parameters by cleaning the graphene surface. Graphene was directly synthesized on glass and quartz substrates with final sheet resistance of $1.3 \mathrm{k} \Omega / \mathrm{sq}$ and transmittance of $80 \%$, resulting in a figure of merit of $\sigma_{\mathrm{DC}} / \sigma_{\mathrm{OP}}=1.24$.

An extremely low substrate temperature $\left(150^{\circ} \mathrm{C}\right)$ growth technique was adopted by Park et al. who used a thin (10 $\mathrm{nm}$ ) Ti layer as a catalytic substrate on PET and glass, due to its strong affinity to carbon [137]. DC sputtered Ti layer was naturally oxidized into $\mathrm{TiO}_{2}$ via exposure to atmospheric oxygen during sample transfer and it was reduced via annealing at $150^{\circ} \mathrm{C}$ in $\mathrm{H}_{2}$ atmosphere. The growth was initiated by a $1100^{\circ} \mathrm{C}$ heating zone upstream of the growth substrate to decompose the hydrocarbon precursor $\left(\mathrm{CH}_{4}\right)$, the growth substrate itself was placed downstream at a $150^{\circ} \mathrm{C}$ zone at $0.6 \mathrm{~Pa}$ pressure in a $\mathrm{CH}_{4} / \mathrm{H}_{2}$ atmosphere. This technique resulted in graphene with transmittance of $97.5 \%$ and sheet resistance of $618 \Omega / \mathrm{sq}\left(\sigma_{\mathrm{DC}} / \sigma_{\mathrm{OP}}=24.1\right)$.

This low-temperature growth technique was improved upon by Tran et al. who used the same technique, but the graphene growth and DC sputtering were done in situ and the thermal graphene growth was replaced with a plasma assisted CVD [138]. Using in situ system allowed avoiding the thermal reduction of $\mathrm{TiO}_{2}$ and the plasma assisted CVD removed the need for a high-temperature $\mathrm{CH}_{4}$ decomposition zone. The growth temperature was the same $150^{\circ} \mathrm{C}$ with the decomposition done in a horizontal $70 \mathrm{~W}$ RF plasma. This horizontal plasma avoids ion bombardment of the growth substrate. The graphene was grown in $\mathrm{Ar} /$ $\mathrm{CH}_{4} / \mathrm{H}_{2}$ atmosphere at $2.4 \times 10^{2} \mathrm{~Pa}$ pressure and it had a 
remarkably low sheet resistance of $81 \Omega / \mathrm{sq}$ at $85.6 \%$ transmittance on a flexible polyestersulfone (PES) substrate ( $\sim 87.8 \%$ of pure PES substrate) and extremely low $I_{\mathrm{D}} / I_{\mathrm{G}}$ ratio of 0.01 . This results in a figure of merit of $\sigma_{\mathrm{DC}} / \sigma_{\mathrm{OP}}=29$.

Doping is an important aspect of transparent graphene electrodes, because it can be used to increase the conductivity of the sample with negligible effect on transparency. Gold chloride $\left(\mathrm{AuCl}_{3}\right)$ has been used widely as a p-type dopant for graphene. Different gold complexes $\left(\mathrm{Au}_{2} \mathrm{~S}, \mathrm{AuBr}_{3}, \mathrm{Au}(\mathrm{OH})_{3}\right)$ for graphene doping were investigated by Kwon et al. [139], because $\mathrm{S}, \mathrm{Br}$ and $\mathrm{OH}$ have stronger bonds to gold than $\mathrm{Cl}$, suggesting that $\mathrm{S}, \mathrm{Br}$ and $\mathrm{OH}$ anions could improve the thermal stabilities of the $\mathrm{Au}$ complexes. It was found out that indeed the bond strength and electronegativity of the anion are related to the dopant's thermal stability; the $\mathrm{Au}(\mathrm{OH})_{3}$ being the most stable on all measurements. Even though it was the most stable, it also provided the least amount of doping. This was measured from work function shift after the doping, where the work function increased from 4.3 to 5.0, 4.8, 4.6 and $4.9 \mathrm{eV}$, for $\mathrm{AuBr}_{3}, \mathrm{Au}_{2} \mathrm{~S}, \mathrm{Au}(\mathrm{OH})_{3}$, and $\mathrm{AuCl}_{3}$ dopants, respectively. This is also reflected in the sheet resistance measurements, where it decreased from 800 1100 to $530,600,820$ and $300 \Omega / \mathrm{sq}$ with transmittances of $95 \%, 86 \%, 93 \%$ and $96 \%\left(\sigma_{\mathrm{DC}} / \sigma_{\mathrm{OP}}=13.7,4.0,6.2,30.5\right)$ for $\mathrm{AuBr}_{3}, \mathrm{Au}_{2} \mathrm{~S}, \mathrm{Au}(\mathrm{OH})_{3}$, and $\mathrm{AuCl}_{3}$ dopants, respectively.

Jang et al. further expanded the study of doping graphene by comparing the time-evolution, structural, optical and electrical properties of three commonly used pdopants: $\mathrm{HNO}_{3}, \mathrm{AuCl}_{3}$ and $\mathrm{RhCl}_{3}$ [140]. Each dopant introduced nanoparticles on the graphene surface, increasing the surface roughness from 0.34 to $1.88,3.47$ and 4.18 nm for $\mathrm{HNO}_{3}, \mathrm{RhCl}_{3}$ and $\mathrm{AuCl}_{3}$, respectively. $\mathrm{HNO}_{3}$ doping introduces smallest nanoparticles with smallest density. This is also reflected in the transmittance measurements, where the transmittance of pristine graphene $97.7 \%$ is decreased to $91 \%, 93 \%$ and $96 \%$ for $\mathrm{AuCl}_{3}, \mathrm{RhCl}_{3}$ and $\mathrm{HNO}_{3}$, respectively. $\mathrm{AuCl}_{3}$ and $\mathrm{RhCl}_{3}$ are the most stable dopants, as their respective sheet resistances (500 and $220 \Omega / \mathrm{sq}$ ) increased only $19 \%$ during a 20-day stability experiment, whereas $\mathrm{HNO}_{3}$ increased up to $19 \%$. It was concluded that $\mathrm{RhCl}_{3}$ is the most stable dopant with the least degradation to transmittance and carrier mobilities.

The aforementioned doping methods have been for $\mathrm{p}$ doping, but complementing this, Bult et al. tested hydrazine and polyethyleneimine (PEI) as n-type dopants for graphene [141]. It was observed that PEI has good stability in air, in comparison to hydrazine and that PEI results in similar doping levels and mobilities as hydrazine. All transfers were done using dry transfer via thermal release tape, instead of the more common wet transfer with PMMA. The resulting sheet resistance for four-layer hydrazine doped graphene is $50 \Omega / \mathrm{sq}$ with $89 \%$ transmission. For a single-layer, sheet resistances of 380 and 397 $\Omega / \mathrm{sq}$ with transmittance of $96 \%$ were measured for hydrazine doping with PEI overcoat and for PEI-doped graphene, respectively. Doping had negligible effect on transmittance.

Generally doping is done chemically either after the growth, or during the growth via dopant gases. These methods use adsorbed species that are electron acceptors or donors, meaning that their long-term stability can be of problem due to desorption. Furthermore, the methods commonly incorporate foreign atoms on the graphene, making it difficult to reproduce [142]. Multiple other doping methods have been designed to mend these difficulties. Chae et al. sputtered aluminum nitride (AlN) layer on top of graphene to act as a buffer layer for evaporated nickel pads [143], see Fig. 5(a). Nickel atoms were injected from the pads to the graphene by applying voltages $(3-5 \mathrm{~V})$ through two separate pads, forming a conductive bridge between the two. The injected nickel atoms act as n-dopants, decreasing the sheet resistance from $712 \pm 75.2$ to $216 \pm 46.1 \Omega /$ sq with negligible effect on the transmittance of $\sim 95 \%\left(\sigma_{\mathrm{DC}} / \sigma_{\mathrm{OP}}=33.6\right)$. The method indicated that no processing residues have remained, and that the nickel-atoms physically diffused into the graphene structure as intercalants. Another way of incorporating the dopants into the graphene structure is to use a plasma to break carbon bonds and replace the carbon atoms with a particular dopant, however, this process easily introduces defects on the graphene plane [144]. In order to decrease the amount of defects produced by plasma doping, Pham et al. used inductively coupled chlorine plasma with a dual metal mesh assembly, as shown in Fig. 5(b), designed to confine low-energy radicals to prevent damaging the graphene layer during the plasma treatment [16]. Sheet resistances of 305,118 and $72 \Omega /$ sq with transmissions of $98.2 \%, 97.3 \%$ and $95.64 \%$ were achieved for mono-, bi-, and tri-layer graphene, where the subsequent layers act as capping layers for the chlorine dopants. Undoped monolayer graphene showed sheet resistance of $\sim 600 \Omega / \mathrm{sq}$. No change in sheet resistance was found after four months in air environment for the bi- and tri-layer doped graphene (no data on monolayer). Figures of merit were 67.7, 115.9 and 116.2 for the mono-, bi- and tri-layer graphene, respectfully. Table 2 includes all the previously discussed results as well as multiple others with the best results having figures of merit over a hundred to up to over 400.

\section{Applications}

Graphene has many potential applications due to its unique properties. There is a need for new flexible and highly robust materials for next-generation electronics, and 


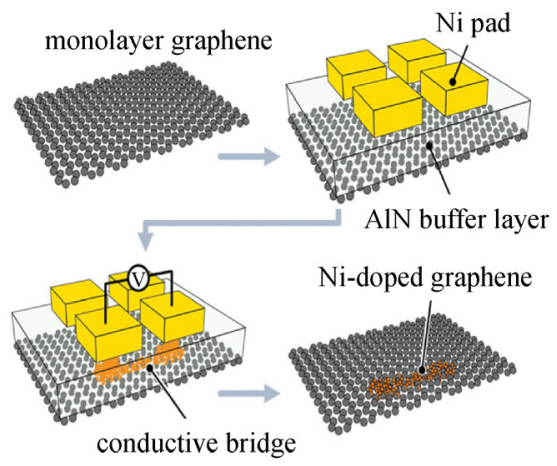

(a)

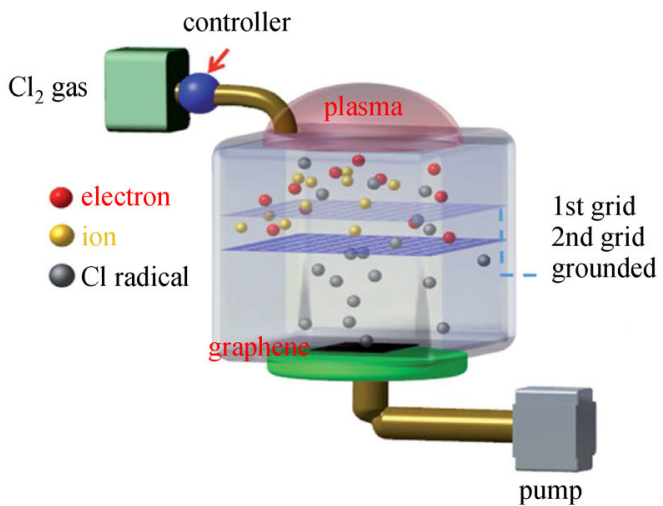

(b)

Fig. 5 (a) Schematic of electrical injection of nickel atoms as p-type dopant by Chae et al., made with an AlN buffer layer. Adapted from Ref. [143]. (b) Chlorine doping of graphene in ICP by Pham et al., with two metal meshes to confine low energy radicals and protect the graphene layer. Adapted from Ref. [16]

graphene has both qualities. Transparency is interesting for semi-transparent solar cells and useful in display technologies. High surface-to-volume ratio is interesting in chemical reactions and battery technologies.

Solar cells are a particularly interesting application field for graphene as their commercial use has been increasing in the past decade. Graphene is a fantastic material for next-generation solar cells, for example, because of its flexibility, conductive properties, and transparency. High transparency is especially interesting in the field of semitransparent solar cells for building integrated photovoltaics (e.g., solar cells on windows). As has been previously mentioned in this work, ITO is prone to micro-cracks under bending which decrease its conductivity significantly. Furthermore, ITO can be problematic when using poly(styrenesulfonate) doped poly(3,4-ethylenedioxythiophene) (PEDOT:PSS), a common hole transport layer, because it has been shown to induce (reversible) cell degradation due to its acidity [155].

Polymer based solar cells are an attractive type of solar cells that can be ecological, cheap, and flexible $[156,157]$, but having a smaller power conversion efficiency (PCE) than other solar cell types [158-160]. La Notte et al. used doped four-layer CVD graphene (on glass) as an ITO alternative in an inverted polymer solar cell with a common PEDOT:PSS layer to allow typical solution processing. Similar average PCEs were achieved using both transparent electrodes $(2.82 \pm 0.15 \%$ for graphene and $3.56 \pm 0.25 \%$ for ITO) over eight devices [161]. An improved version on standard graphene/PEDOT:PSS can be done by introducing a $\mathrm{MoO}_{3}$ electron blocking layer, which was shown by Park et al. [162], where over a tenfold improvement of PCE was achieved (from $0.5 \%$ to $7.1 \%$ ) on a flexible substrate. PEDOT:PSS is a common hole transport layer, but functionalized graphene can be used instead of it as a hole transport layer, using for example, graphene oxide [163] or high sheet-resistance
CVD graphene [164]. Laser patterning of graphene is a well-established technique [165], and can be applied here as well, and oxygen-plasma can be used instead of chemical doping to increase wettability of the graphene layer, which increases the PCE [166]. Many other works on applications of graphene on polymer solar cells have been done, using it as an electrode layer [161,166-168], including it in a hybrid-polymer layer $[169,170]$ or as hybrid electrode [171-174]. Graphene has also been applied to dye sensitized solar cells, e.g., in counterelectrodes [175-178], nanocomposite matrices [179,180] and photoanodes [181-183]. Another interesting thirdgeneration solar cell type is perovskite based solar cells (PSCs), which reached PCE of 25\% [184] in 2019, rivaling that of current commercial Si-based solar cells. PCEs are notorious for degrading (via e.g., light-induced degradation $[185,186]$, humidity $[187,188]$, and perovskite-metal reactions due to interdiffusion $[189,190])$, and even the best PSCs have lifetimes of only thousands of hours [191]. Graphene has been used as a stabilizing agent as, e.g., a protective layer [192-194], and transport layer [195-199] and electrode material [200-203].

Graphene is an interesting material in biosensing applications due to its two-dimensionality, or rather its lack of bulk, giving it extremely high surface-to-volume ratio. Potentially every single atom of the structure can be affected by an adsorbate, making graphene's inherent sensitivity high. Graphene based field-effect-transistor (GFET) sensor is a common and reliable sensor [204], and has been used recently e.g., for early detection of the Zika-virus [205], RNA and DNA detection down to $10^{-17} \mathrm{~mol} / \mathrm{L}$ concentrations [206,207], in operando TEM measurements of neuropeptide capture and release [208] as well as detection of SARS-CoV-2 virus [209], the cause of the global COVID-19 pandemic of 2020. Other measurement schemes can be used as well, such as, Hall effect in standard [210], gated [211] and photonic spin [212,213] 
Table 2 Summary of different graphene based transparent electrodes, where $R_{\mathrm{s}}, T, \sigma_{\mathrm{DC}} / \sigma_{\mathrm{OP}}$ and $R_{\text {change }}$ refer to sheet resistance, transmittance (at $550 \mathrm{~nm}$ unless otherwise specified), figure of merit and decrease of sheet resistance due to doping, respectively. Substrate refers to the substrate where $R_{\mathrm{S}}$ and $T$ are measured on, if two substrates are given, then their corresponding measurements are given in brackets after the substrate

\begin{tabular}{|c|c|c|c|c|c|c|}
\hline$\overline{R_{\mathrm{S}} /\left(\Omega \cdot \mathrm{sq}^{-1}\right)}$ & $T / \%$ & $\sigma_{\mathrm{DC}} / \sigma_{\mathrm{OP}}$ & $R_{\text {change }} / \%$ & substrate & dopant (n/p) & Ref. \\
\hline$\overline{100}$ & 90 & 35 & - & - & - & minimum industry requirement [70] \\
\hline 3600 & 85.7 & 0.66 & - & flexible glass & - & {$[134]^{\mathrm{a})}$} \\
\hline 1645 & 81 & 1.03 & - & quartz & - & [104] \\
\hline 1300 & 80 & 1.24 & - & quartz & - & {$[136]^{\mathrm{a})}$} \\
\hline 1170 & 88 & 2.44 & - & PET & - & [103] \\
\hline 661 & 83.7 & 3.09 & - & glass & - & {$[135]^{\mathrm{a})}$} \\
\hline 600 & 86 & 4.01 & 37 & $\mathrm{SiO}_{2}\left(R_{\mathrm{s}}\right) /$ glass $(T)$ & $\mathrm{Au}_{2} \mathrm{~S}(\mathrm{p})$ & [139] \\
\hline 230 & 71 & 4.39 & - & PET & - & [145] \\
\hline 280 & 76 & 4.58 & - & quartz & - & [98] \\
\hline 700 & 90 & 4.98 & - & $\mathrm{SiO}_{2}\left(R_{\mathrm{s}}\right) /$ glass $(T)$ & - & [146] \\
\hline 350 & $83^{\text {b) }}$ & 5.52 & - & - & pyridine $(\mathrm{n})^{\mathrm{c})}$ & [147] \\
\hline 445 & 87 & 5.87 & 47 & $\mathrm{SiO}_{2}\left(R_{\mathrm{s}}\right) / \mathrm{PET}(T)$ & $\mathrm{AuCl}_{3}(\mathrm{p})$ & [148] \\
\hline 820 & 93 & 6.22 & 14 & $\mathrm{SiO}_{2}\left(R_{\mathrm{s}}\right) /$ glass $(T)$ & $\mathrm{Au}(\mathrm{OH})_{3}(\mathrm{p})$ & [139] \\
\hline 1150 & 97 & 10.7 & - & glass & - & [149] \\
\hline 200 & 86.7 & 12.7 & 87 & EVA + PET & $\mathrm{HNO}_{3}(\mathrm{p})$ & {$[150]$} \\
\hline 530 & 95 & 13.7 & 44 & $\mathrm{SiO}_{2}\left(R_{\mathrm{s}}\right) /$ glass $(T)$ & $\mathrm{AuBr}_{3}(\mathrm{p})$ & [139] \\
\hline 350 & 93 & 14.6 & 52 & - & $\mathrm{RhCl}_{3}(\mathrm{p})$ & [140] \\
\hline 150 & 87 & 17.4 & 66 & $\mathrm{SiO}_{2}\left(R_{\mathrm{S}}\right) / \mathrm{PET}(T)$ & $\mathrm{AuCl}_{3}(\mathrm{p})$ & [148] \\
\hline 220 & 91 & 17.8 & 70 & - & $\mathrm{AuCl}_{3}(\mathrm{p})$ & [140] \\
\hline 500 & 96 & 18.3 & 32 & - & $\mathrm{HNO}_{3}(\mathrm{p})$ & [140] \\
\hline $118^{\mathrm{d})}$ & 84.9 & 18.7 & 56 & glass & $\operatorname{CsF}(n)$ & [151] \\
\hline 129 & 88 & 22.1 & 70 & $\mathrm{SiO}_{2}\left(R_{\mathrm{S}}\right) /$ sapphire $(T)$ & $\left.\operatorname{TFSA}(\mathrm{p})^{\mathrm{e}}\right)$ & [152] \\
\hline 550 & 97 & 22.3 & - & $\mathrm{PVDF}^{\mathrm{f}}$ & - & [153] \\
\hline 380 & 96 & 24.1 & 42 & glass & hydrazine (n) & [141] \\
\hline 618 & 97.5 & 24.1 & - & glass & - & {$[137]^{\mathrm{a})}$} \\
\hline 500 & 97.1 & 25.4 & - & quartz & - & [154] \\
\hline 299 & 95.7 & 28.4 & 62 & $\mathrm{SiO}_{2}\left(R_{\mathrm{s}}\right) /$ quartz $(T)$ & $\mathrm{HNO}_{3}(\mathrm{p})$ & [105] \\
\hline 81 & 85.6 & 29 & - & $\mathrm{PES}^{\mathrm{g})}$ & - & {$[138]^{\mathrm{a})}$} \\
\hline 300 & 96 & 30.5 & 68 & $\mathrm{SiO}_{2}\left(R_{\mathrm{s}}\right) /$ glass $(T)$ & $\mathrm{AuCl}_{3}(\mathrm{p})$ & [139] \\
\hline 216 & 95 & 33.6 & 70 & quartz & $\mathrm{Ni}(\mathrm{p})^{\mathrm{h})}$ & [143] \\
\hline 367 & 97.3 & 37.3 & - & PET & - & [101] \\
\hline 215 & 96 & 42.5 & 44 & $\mathrm{SiO}_{2}\left(R_{\mathrm{s}}\right) /$ glass $(T)$ & $\mathrm{Au} N \mathrm{NP}(\mathrm{p})$ & [109] \\
\hline 320 & 98 & 58.0 & - & cellulose & - & [107] \\
\hline 50 & 89 & 62.8 & 76 & glass & hydrazine (n) & [141] \\
\hline 305 & 98.2 & 67.7 & 49 & PET & $\mathrm{Cl}$ plasma (p) & [16] \\
\hline $30^{\mathrm{d})}$ & 90 & 116 & 25 & $\mathrm{SiO}_{2}\left(R_{\mathrm{s}}\right) / \mathrm{PET}(T)$ & $\mathrm{HNO}_{3}(\mathrm{p})$ & [106] \\
\hline $118^{\mathrm{i})}$ & 97.3 & 116 & 80 & PET & $\mathrm{Cl}$ plasma (p) & {$[16]$} \\
\hline 115 & 97.5 & 135 & 50 & $\mathrm{SiO}_{2}\left(R_{\mathrm{s}}\right) / \mathrm{PET}(T)$ & $\mathrm{HNO}_{3}(\mathrm{p})$ & [106] \\
\hline 25 & 96.5 & 419 & 83 & parylene-C & $\mathrm{HNO}_{3}(\mathrm{p})$ & [108] \\
\hline
\end{tabular}

Notes: a) PECVD directly on dielectric substrate. b) At $633 \mathrm{~nm}$. c) $I n$-situ doping. d) Stacked four-layer graphene. e) Bis(trifluoromethanesulfonyl)amide.

f) Polyvinylidene fluoride. g) Polyestersulfone. h) Doped via electrical injection. i) Stacked two-layer graphene 
configurations or optical measurements using e.g., fluorescence [214,215], refractive index imaging [216] or surface plasmons [215,217-219]

Terahertz frequency photodetectors are important in many applications, such as, medicine [220], spectroscopy [221] and communications [222]. Its main benefits include its ability to penetrate most dielectrics without being invasive or ionizing, its capability to probe molecular dynamics [223] and the sheer data throughput for communications. Graphene has been used in these detection technologies in many ways e.g., as a ballistic rectifier [224], or on antennas on flexible substrates [225], or using more conventional GFETs [226-228]. Graphene has also been used in $\mathrm{THz}$ modulation [227,229].

Displays have integrated themselves in our society as computers have gained traction. Modern displays use technologies such as, organic light-emitting diodes (OLEDs), micro-LEDs, plasma, and liquid crystal displays (LCDs). Within these technologies, graphene has been used as an ITO replacement in standard [230,231] and flexible [232-234] OLED displays. Graphene has also been used in flexible alternating-current electroluminescent displays [235-237], as well as in LCDs [238-240]. Other applications of graphene in display technologies include increasing standard ITO OLED performance [241] and using as electrodes for GaN micro-LEDs [242].

\section{Conclusions and outlook}

Graphene is a one atom thick layer of carbon with multiple properties ideal for transparent electrodes. It is mechanically stable, flexible, optically near-transparent, and an excellent electrical conductor. Liquid exfoliation allows fast processing in bulk for fabricating graphene electrodes. Even though the best electrode properties rival that of CVD, liquid exfoliation still has multiple issues. Almost all the liquid exfoliation techniques use surfactants, organic solvents, or graphene oxide. Even liquid exfoliation in an electrochemical cell introduces a significant amount of oxides which ideally need to be reduced to their nonoxidized state. The glaring issue is that each technique requires high temperatures for defect removal which prevents their use on low-melting-point plastics. Chemical treatments can be used to reduce these temperatures, but the required temperatures are still above the melting points of common plastics. A way to circumvent the issues with high-temperature defect removal/reduction step, would be to use the high-temperature annealing on a rigid carrier from which the graphene is subsequently transferred to a flexible substrate. Unfortunately, this introduces another processing step and a transfer process generally introduces further basal-plane defects. Additionally, defect removal/ reduction step is not perfect and liquid exfoliated graphene is generally much more defective than CVD. Also, many of the discussed methods have a very long process time (e.g., long-time sonication or centrifugation) in order to reach high enough graphene concentrations, or laterally large flakes or few-layer thicknesses. Tens or even hundreds of hours of processing time are problematic when the methods themselves do not scale up indefinitely. For instance, the energy transfer from a sonicator to the graphite flakes limits the processing volume of this method. Shear mixing scales much better, but it has been investigated much less than sonication. Toxic chemicals in Hummer's method for producing graphite oxide are also a problem for industry, as well is the cost of good solvents for pristine graphene. In the end, liquid exfoliation is an interesting technique due to its potential for massive production volumes but at its current state it introduces too many defects that require complicated processing to remove well. These issues might not be such a problem if the quality of the resulting film would reflect it; unfortunately, this is usually not the case. Some electrochemically produced graphene electrodes do have viable figures of merit, but they are still at least an order of magnitude away from being a viable ITO replacement.

CVD produces much higher quality graphene electrodes, many of the articles discussed in this review have figures of merit approaching and surpassing the minimum standard for industry. Unfortunately, for industrial adaptation, the result should be much better than the minimum standard for industry to abandon ITO. CVD has other issues as well; it is inherently expensive and does not scale as easily as liquid exfoliation. Graphene transfer process is also problematic. The use of metal etchants increase cost, and the manual transfer processes are a serious hindrance for large-scale production. Moreover, the transfer processes also introduce defects to the graphene lattice that can be problematic to remove adequately. However, the transfer process can be avoided if the growth is done directly on a dielectric substrate via PECVD, which would make the process much less manual and would increase the throughput substantially.

In the end, graphene shows excellent potential for transparent graphene electrodes, especially as flexible electronics are gaining traction. Future work on liquid exfoliation should be targeted towards new techniques or solvents that either intrinsically introduce less defects, or that remove defects (mainly oxides) more efficiently in order to increase the figure of merit high enough for industrial electrode applications. Furthermore, current reduction methods mainly involve high temperatures, thus lowering these while maintaining good reduction is imperative for industrial processing of flexible electronics. In CVD, the issues are the manual and mechanical transfer processes as well the loss of the growth substrate after etching. There is a need to research cleaner transfer processes that do not leave residues and are scalable for industrial use in thermal CVD processing. PECVD has major potential for removing many issues with thermal CVD regarding transfer processing, but it still requires 
higher quality graphene to be competitive. Fortunately, the quality of PECVD graphene has improved substantially recently, which makes it a very valid industrial scale processing technique. The focus for PECVD should be to reduce the number of defects from the highly reactive and high velocity ions.

Acknowledgements The work has received funding from the European Union's Horizon 2020 research and innovation programme under grant agreement GrapheneCore2 number 785219, and GrapheneCore3 number 881603. We acknowledge the financial support from Academy of Finland (projects 298297 and 320167-PREIN Flagship).

Funding note Open access funding provided by Aalto University.

Open Access This article is licensed under a Creative Commons Attribution 4.0 International License, which permits use, sharing, adaptation, distribution and reproduction in any medium or format, as long as you give appropriate credit to the original author(s) and the source, provide a link to the Creative Commons licence, and indicate if changes were made.

The images or other third party material in this article are included in the article's Creative Commons licence, unless indicated otherwise in a credit line to the material. If material is not included in the article's Creative Commons licence and your intended use is not permitted by statutory regulation or exceeds the permitted use, you will need to obtain permission directly from the copyright holder.

To view a copy of this licence, visit http://creativecommons.org/licenses/ by-nc/4.0/.

\section{References}

1. Novoselov K S, Geim A K, Morozov S V, Jiang D, Zhang Y, Dubonos S V, Grigorieva I V, Firsov A A. Electric field effect in atomically thin carbon films. Science, 2004, 306(5696): 666-669

2. Peierls R. Quelques propriétés typiques des corps solides. Annales de l'Institut Henri Poincaré, 1935, 5(3): 177-222

3. Landau L D. On the theory of phase transitions. Ukrainian Journal of Physical, 1937, 11: 19-32

4. Mermin N D. Crystalline order in two dimensions. Physical Review, 1968, 176(1): 250-254

5. Nelson D R, Peliti L. Fluctuations in membranes with crystalline and hexatic order. Journal de Physique (Paris), 1988, 49(1): 139

6. Banszerus L, Schmitz M, Engels S, Goldsche M, Watanabe K, Taniguchi T, Beschoten B, Stampfer C. Ballistic transport exceeding $28 \mu \mathrm{m}$ in CVD grown graphene. Nano Letters, 2016, 16(2): 1387-1391

7. Mayorov A S, Gorbachev R V, Morozov S V, Britnell L, Jalil R, Ponomarenko L A, Blake P, Novoselov K S, Watanabe K, Taniguchi T, Geim A K. Micrometer-scale ballistic transport in encapsulated graphene at room temperature. Nano Letters, 2011, 11(6): 2396-2399

8. Wang L, Meric I, Huang P Y, Gao Q, Gao Y, Tran H, Taniguchi T, Watanabe K, Campos L M, Muller D A, Guo J, Kim P, Hone J, Shepard K L, Dean C R. One-dimensional electrical contact to a two-dimensional material. Science, 2013, 342(6158): 614-617

9. Hwang E H, Adam S, Sarma S D. Carrier transport in twodimensional graphene layers. Physical Review Letters, 2007, 98 (18): 186806
10. Lee G H, Cooper R C, An S J, Lee S, van der Zande A, Petrone N, Hammerberg A G, Lee C, Crawford B, Oliver W, Kysar J W, Hone J. High-strength chemical-vapor-deposited graphene and grain boundaries. Science, 2013, 340(6136): 1073-1076

11. Xu J, Yuan G, Zhu Q, Wang J, Tang S, Gao L. Enhancing the strength of graphene by a denser grain boundary. ACS Nano, 2018, 12(5): 4529-4535

12. Lee C, Wei X, Kysar J W, Hone J. Measurement of the elastic properties and intrinsic strength of monolayer graphene. Science, 2008, 321(5887): 385-388

13. Nair R R, Blake P, Grigorenko A N, Novoselov K S, Booth T J, Stauber T, Peres N M R, Geim A K. Fine structure constant defines visual transparency of graphene. Science, 2008, 320(5881): 1308

14. Balandin A A. Thermal properties of graphene and nanostructured carbon materials. Nature Materials, 2011, 10(8): 569-581

15. Zheng Q, Ip W H, Lin X, Yousefi N, Yeung K K, Li Z, Kim J K. Transparent conductive films consisting of ultralarge graphene sheets produced by Langmuir-Blodgett assembly. ACS Nano, 2011, 5(7): 6039-6051

16. Pham V P, Mishra A, Young Yeom G. The enhancement of Hall mobility and conductivity of CVD graphene through radical doping and vacuum annealing. RSC Advances, 2017, 7(26): 16104-16108

17. Suzuki S, Yoshimura M. Chemical stability of graphene coated silver substrates for surface-enhanced raman scattering. Scientific Reports, 2017, 7(1): 14851

18. Pisana S, Lazzeri M, Casiraghi C, Novoselov K S, Geim A K, Ferrari A C, Mauri F. Breakdown of the adiabatic BornOppenheimer approximation in graphene. Nature Materials, 2007, 6(3): 198-201

19. Novoselov K S, Jiang Z, Zhang Y, Morozov S V, Stormer H L, Zeitler U, Maan J C, Boebinger G S, Kim P, Geim A K. Roomtemperature quantum Hall effect in graphene. Science, 2007, 315 (5817): 1379

20. Zhang Y, Tan Y W, Stormer H L, Kim P. Experimental observation of the quantum Hall effect and Berry's phase in graphene. Nature, 2005, 438(7065): 201-204

21. Bolotin K I, Ghahari F, Shulman M D, Stormer H L, Kim P. Observation of the fractional quantum Hall effect in graphene. Nature, 2009, 462(7270): 196-199

22. Qiao Z, Yang S A, Feng W, Tse W K, Ding J, Yao Y, Wang J, Niu Q. Quantum anomalous Hall effect in graphene from Rashba and exchange effects. Physical Review B: Condensed Matter and Materials Physics, 2010, 82(16): 161414

23. Levy D, Castellón E. Transparent Conductive Materials: Materials, Synthesis, Characterization, Applications. New York: John Wiley \& Sons, 2018

24. Hu Y, Diao X, Wang C, Hao W, Wang T. Effects of heat treatment on properties of ITO films prepared by rf magnetron sputtering. Vacuum, 2004, 75(2): 183-188

25. Alzoubi K, Hamasha M M, Lu S, Sammakia B. Bending fatigue study of sputtered ITO on flexible substrate. Journal of Display Technology, 2011, 7(11): 593-600

26. Im H G, Jeong S, Jin J, Lee J, Youn D Y, Koo W T, Kang S B, Kim H J, Jang J, Lee D, Kim H K, Kim I D, Lee J Y, Bae B S. Hybrid crystalline-ITO/metal nanowire mesh transparent electrodes and 
their application for highly flexible perovskite solar cells. NPG Asia Materials, 2016, 8(6): e282

27. Park S H, Lee S J, Lee J H, Kal J, Hahn J, Kim H K. Large area rollto-roll sputtering of transparent ITO/Ag/ITO cathodes for flexible inverted organic solar cell modules. Organic Electronics, 2016, 30 : $112-121$

28. Novoselov K S, Geim A K, Morozov S V, Jiang D, Zhang Y, Dubonos S V, Grigorieva I V, Firsov A A. Electric field effect in atomically thin carbon films. Science, 2004, 306(5696): 666-669

29. Suslick K S. Sonochemistry. Science, 1990, 247(4949): 14391445

30. Yi M, Shen Z. A review on mechanical exfoliation for the scalable production of grapheme. Journal of Materials Chemistry A, Materials for Energy and Sustainability, 2015, 3(22): 11700-11715

31. Chen X, Dobson J F, Raston C L. Vortex fluidic exfoliation of graphite and boron nitride. Chemical Communications (Cambridge), 2012, 48(31): 3703-3705

32. Paton K R, Varrla E, Backes C, Smith R J, Khan U, O'Neill A, Boland C, Lotya M, Istrate O M, King P, Higgins T, Barwich S, May P, Puczkarski P, Ahmed I, Moebius M, Pettersson H, Long E, Coelho J, O’Brien S E, McGuire E K, Sanchez B M, Duesberg G S, McEvoy N, Pennycook T J, Downing C, Crossley A, Nicolosi V, Coleman J N. Scalable production of large quantities of defect-free few-layer graphene by shear exfoliation in liquids. Nature Materials, 2014, 13(6): 624-630

33. Lin Z, Karthik P S, Hada M, Nishikawa T, Hayashi Y. Simple technique of exfoliation and dispersion of multilayer graphene from natural graphite by ozone-assisted sonication. Nanomaterials (Basel, Switzerland), 2017, 7(6): 125

34. Blake P, Brimicombe P D, Nair R R, Booth T J, Jiang D, Schedin F, Ponomarenko L A, Morozov S V, Gleeson H F, Hill E W, Geim A K, Novoselov K S. Graphene-based liquid crystal device. Nano Letters, 2008, 8(6): 1704-1708

35. Hernandez Y, Nicolosi V, Lotya M, Blighe F M, Sun Z, De S, McGovern I T, Holland B, Byrne M, Gun'Ko Y K, Boland J J, Niraj P, Duesberg G, Krishnamurthy S, Goodhue R, Hutchison J, Scardaci V, Ferrari A C, Coleman J N. High-yield production of graphene by liquid-phase exfoliation of graphite. Nature Nanotechnology, 2008, 3(9): 563-568

36. Bunch J S, Yaish Y, Brink M, Bolotin K, McEuen P L. Coulomb oscillations and Hall effect in quasi-2D graphite quantum dots. Nano Letters, 2005, 5(2): 287-290

37. Hernandez Y, Lotya M, Rickard D, Bergin S D, Coleman J N. Measurement of multicomponent solubility parameters for graphene facilitates solvent discovery. Langmuir, 2010, 26(5): 32083213

38. Bergin S D, Nicolosi V, Streich P V, Giordani S, Sun Z, Windle A H, Ryan P, Niraj N P P, Wang Z T T, Carpenter L, Blau W J, Boland J J, Hamilton J P, Coleman J N. Towards solutions of single-walled carbon nanotubes in common solvents. Advanced Materials, 2008, 20(10): 1876-1881

39. Coleman J N. Liquid-phase exfoliation of nanotubes and graphene. Advanced Functional Materials, 2009, 19(23): 3680-3695

40. Liang Y T, Hersam M C. Highly concentrated graphene solutions via polymer enhanced solvent exfoliation and iterative solvent exchange. Journal of the American Chemical Society, 2010, 132
(50): 17661-17663

41. Park K H, Kim B H, Song S H, Kwon J, Kong B S, Kang K, Jeon $\mathrm{S}$. Exfoliation of non-oxidized graphene flakes for scalable conductive film. Nano Letters, 2012, 12(6): 2871-2876

42. Tomašević-Ilić T, Pešić J, Milošević I, Vujin J, Matković A, Spasenović M, Gajić R. Transparent and conductive films from liquid phase exfoliated graphene. Optical and Quantum Electronics, 2016, 48(6): 319

43. Majee S, Song M, Zhang S L, Zhang Z B. Scalable inkjet printing of shear-exfoliated graphene transparent conductive films. Carbon, 2016, 102: 51-57

44. Narayan R, Kim S O. Surfactant mediated liquid phase exfoliation of graphene. Nano Convergence, 2015, 2(1): 20

45. Liu N, Luo F, Wu H, Liu Y, Zhang C, Chen J. One-step ionicliquid-assisted electrochemical synthesis of ionic-liquid-functionalized graphene sheets directly from graphite. Advanced Functional Materials, 2008, 18(10): 1518-1525

46. Khan U, O’Neill A, Lotya M, De S, Coleman J N. Highconcentration solvent exfoliation of graphene. Small, 2010, 6(7): 864-871

47. Li J, Yan H, Dang D, Wei W, Meng L. Salt and water co-assisted exfoliation of graphite in organic solvent for efficient and large scale production of high-quality graphene. Journal of Colloid and Interface Science, 2019, 535: 92-99

48. Zhang M, Parajuli R R, Mastrogiovanni D, Dai B, Lo P, Cheung W, Brukh R, Chiu P L, Zhou T, Liu Z, Garfunkel E, He H. Production of graphene sheets by direct dispersion with aromatic healing agents. Small, 2010, 6(10): 1100-1107

49. Liu L, Rim K T, Eom D, Heinz T F, Flynn G W. Direct observation of atomic scale graphitic layer growth. Nano Letters, 2008, 8(7): 1872-1878

50. Tung T T, Yoo J, Alotaibi F K, Nine M J, Karunagaran R, Krebsz M, Nguyen G T, Tran D N H, Feller J F, Losic D. Graphene oxideassisted liquid phase exfoliation of graphite into graphene for highly conductive film and electromechanical sensors. ACS Applied Materials \& Interfaces, 2016, 8(25): 16521-16532

51. Majee S, Song M, Zhang S L, Zhang Z B. Scalable inkjet printing of shear-exfoliated graphene transparent conductive films. Carbon, 2016, 102: 51-57

52. Shin D W, Barnes M D, Walsh K, Dimov D, Tian P, Neves A I S, Wright C D, Yu S M, Yoo J B, Russo S, Craciun M F. A new facile route to flexible and semi-transparent electrodes based on water exfoliated graphene and their single-electrode triboelectric nanogenerator. Advanced Materials, 2018, 30(39): 1802953

53. Fukushima T, Aida T. Ionic liquids for soft functional materials with carbon nanotubes. Chemistry (Weinheim an der Bergstrasse, Germany), 2007, 13(18): 5048-5058

54. Su C Y, Lu A Y, Xu Y, Chen F R, Khlobystov A N, Li L J. Highquality thin graphene films from fast electrochemical exfoliation. ACS Nano, 2011, 5(3): 2332-2339

55. Liu J, Notarianni M, Will G, Tiong V T, Wang H, Motta N. Electrochemically exfoliated graphene for electrode films: effect of graphene flake thickness on the sheet resistance and capacitive properties. Langmuir, 2013, 29(43): 13307-13314

56. Parvez K, Wu Z S, Li R, Liu X, Graf R, Feng X, Müllen K. Exfoliation of graphite into graphene in aqueous solutions of 
inorganic salts. Journal of the American Chemical Society, 2014, 136(16): 6083-6091

57. Zhang Y, Xu Y. Simultaneous electrochemical dual-electrode exfoliation of graphite toward scalable production of high-quality graphene. Advanced Functional Materials, 2019, 29(37): 1902171

58. Roscher S, Hoffmann R, Prescher M, Knittel P, Ambacher O. High voltage electrochemical exfoliation of graphite for high-yield graphene production. RSC Advances, 2019, 9: 29305-29311

59. Hummers W S Jr, Offeman R E. Preparation of graphitic oxide. Journal of the American Chemical Society, 1958, 80(6): 1339

60. Hirata M, Gotou T, Horiuchi S, Fujiwara M, Ohba M. Thin-film particles of graphite oxide 1: high-yield synthesis and flexibility of the particles. Carbon, 2004, 42(14): 2929-2937

61. Shahriary L, Athawale A A. Graphene oxide synthesized by using modified hummers approach. International Journal of Renewable Energy and Environmental Engineering, 2014, 2(1): 58-63

62. Dreyer D R, Todd A D, Bielawski C W. Harnessing the chemistry of graphene oxide. Chemical Society Reviews, 2014, 43(15): 5288-5301

63. Mattevi C, Eda G, Agnoli S, Miller S, Mkhoyan K A, Celik O, Mastrogiovanni D, Granozzi G, Garfunkel E, Chhowalla M. Evolution of electrical, chemical, and structural properties of transparent and conducting chemically derived graphene thin films. Advanced Functional Materials, 2009, 19(16): 2577-2583

64. Wang S J, Geng Y, Zheng Q, Kim J K. Fabrication of highly conducting and transparent graphene films. Carbon, 2010, 48(6): $1815-1823$

65. Geng J, Jung H T. Porphyrin functionalized graphene sheets in aqueous suspensions: from the preparation of graphene sheets to highly conductive graphene films. Journal of Physical Chemistry C, 2010, 114(18): 8227-8234

66. Pham V H, Cuong T V, Hur S H, Shin E W, Kim J S, Chung J S, Kim E J. Fast and simple fabrication of a large transparent chemically-converted graphene film by spray-coating. Carbon, 2010, 48(7): 1945-1951

67. Alahbakhshi M, Fallahi A, Mohajerani E, Fathollahi M R, Taromi F A, Shahinpoor M. High-performance Bi-stage process in reduction of graphene oxide for transparent conductive electrodes. Optical Materials, 2017, 64: 366-375

68. Becerril H A, Mao J, Liu Z, Stoltenberg R M, Bao Z, Chen Y. Evaluation of solution-processed reduced graphene oxide films as transparent conductors. ACS Nano, 2008, 2(3): 463-470

69. Wang J, Liang M, Fang Y, Qiu T, Zhang J, Zhi L. Rod-coating: towards large-area fabrication of uniform reduced graphene oxide films for flexible touch screens. Advanced Materials, 2012, 24(21): 2874-2878

70. De S, Coleman J N. Are there fundamental limitations on the sheet resistance and transmittance of thin graphene films? ACS Nano, 2010, 4(5): 2713-2720

71. Lotya M, Hernandez Y, King P J, Smith R J, Nicolosi V, Karlsson L S, Blighe F M, De S, Wang Z, McGovern I T, Duesberg G S, Coleman J N. Liquid phase production of graphene by exfoliation of graphite in surfactant/water solutions. Journal of the American Chemical Society, 2009, 131(10): 3611-3620

72. De S, King P J, Lotya M, O'Neill A, Doherty E M, Hernandez Y, Duesberg G S, Coleman J N. Flexible, transparent, conducting films of randomly stacked graphene from surfactant-stabilized, oxide-free graphene dispersions. Small, 2010, 6(3): 458-464

73. $\mathrm{Au} \mathrm{C} \mathrm{T,} \mathrm{Ng} \mathrm{C} \mathrm{F,} \mathrm{Liao} \mathrm{M} \mathrm{S.} \mathrm{Methane} \mathrm{dissociation} \mathrm{and} \mathrm{syngas}$ formation on $\mathrm{Ru}, \mathrm{Os}, \mathrm{Rh}, \mathrm{Ir}, \mathrm{Pd}, \mathrm{Pt}, \mathrm{Cu}, \mathrm{Ag}$, and $\mathrm{Au}$ : a theoretical study. Journal of Catalysis, 1999, 185(1): 12-22

74. Nandamuri G, Roumimov S, Solanki R. Chemical vapor deposition of graphene films. Nanotechnology, 2010, 21(14): 145604

75. An H, Lee W J, Jung J. Graphene synthesis on Fe foil using thermal CVD. Current Applied Physics, 2011, 11(4): S81-S85

76. Cushing G W, Johánek V, Navin J K, Harrison I. Graphene growth on $\operatorname{Pt}(111)$ by ethylene chemical vapor deposition at surface temperatures near $1000 \mathrm{~K}$. Journal of Physical Chemistry C, 2015, 119(9): 4759-4768

77. Imamura G, Saiki K. Synthesis of nitrogen-doped graphene on Pt (111) by chemical vapor deposition. Journal of Physical Chemistry C, 2011, 115(20): 10000-10005

78. Zhao L, Rim K T, Zhou H, He R, Heinz T F, Pinczuk A, Flynn G W, Pasupathy A N. Influence of copper crystal surface on the CVD growth of large area monolayer graphene. Solid State Communications, 2011, 151(7): 509-513

79. Sun Z, Yan Z, Yao J, Beitler E, Zhu Y, Tour J M. Growth of graphene from solid carbon sources. Nature, 2010, 468(7323): 549-552

80. Virojanadara C, Syväjarvi M, Yakimova R, Johansson L I, Zakharov A A, Balasubramanian T. Homogeneous large-area graphene layer growth on $6 \mathrm{H}-\mathrm{SiC}(0001)$. Physical Review B: Condensed Matter and Materials Physics, 2008, 78(24): 245403

81. Wassei J K, Mecklenburg M, Torres J A, Fowler J D, Regan B C, Kaner R B, Weiller B H. Chemical vapor deposition of graphene on copper from methane, ethane and propane: evidence for bilayer selectivity. Small, 2012, 8(9): 1415-1422

82. Wan X, Chen K, Liu D, Chen J, Miao Q, Xu J. High-quality largearea graphene from dehydrogenated polycyclic aromatic hydrocarbons. Chemistry of Materials, 2012, 24(20): 3906-3915

83. Backes C, Abdelkader A M, Alonso C, Andrieux-Ledier A, Arenal R, Azpeitia J, Balakrishnan N, Banszerus L, Barjon J, Bartali R, Bellani S, Berger C, Berger R, Bernal Ortega M M, Bernard C, Beton P H, Beyer A, Bianco A, Bøggild P, Bonaccorso F, Barin G B, Botas C, Bueno R A, Carriazo D, Castellanos-Gomez A, Christian M, Ciesielski A, Ciuk T, Cole M T, Coleman J, Coletti C, Crema L, Cun H, Dasler D, Fazio D D, Díez N, Drieschner S, Duesberg G S, Fasel R, Feng X, Fina A, Forti S, Galiotis C, Garberoglio G, García J M, Garrido J A, Gibertini M, Gölzhäuser A, Gómez J, Greber T, Hauke F, Hemmi A, Hernandez-Rodriguez I, Hirsch A, Hodge S A, Huttel Y, Jepsen P U, Jimenez I, Kaiser U, Kaplas T, Kim H, Kis A, Papagelis K, Kostarelos K, Krajewska A, Lee K, Li C, Lipsanen H, Liscio A, Lohe M R, Loiseau A, Lombardi L, López M F, Martin O, Martín C, Martínez L, MartinGago J A, Martínez J I, Marzari N, Mayoral A, Melucci M J, Méndez J, Merino C, Merino P, Meyer A P, Miniussi E, Miseikis V, Mishra N, Morandi V, Munuera C, Muñoz R, Nolan H, Ortolani L, Ott A K, Palacio I, Palermo V, Parthenios J, Pasternak I, Patane A, Prato M, Prevost H, Prudkovskiy V, Pugno N, Rojo T, Rossi A, Ruffieux P, Samorì P, Schué L, Setijadi E, Seyller T, Speranza G, Stampfer C, Stenger I, Strupinski W, Svirko Y, Taioli S, Teo K B 
K, Testi M, Tomarchio F, Tortello M, Treossi E, Turchanin A, Vazquez E, Villaro E, Whelan P R, Xia Z, Yakimova R, Yang S, Yazdi G R, Yim C, Yoon D, Zhang X, Zhuang X, Colombo L, Ferrari A C, Garcia-Hernandez M. Production and processing of graphene and related materials. 2D Materials, 2020, 7(2): 022001

84. Losurdo M, Giangregorio M M, Capezzuto P, Bruno G. Graphene CVD growth on copper and nickel: role of hydrogen in kinetics and structure. Physical Chemistry Chemical Physics, 2011, 13(46): 20836-20843

85. Gajewski G, Pao C W. Ab initio calculations of the reaction pathways for methane decomposition over the $\mathrm{Cu}$ (111) surface. Journal of Chemical Physics, 2011, 135(6): 064707

86. Kim H, Mattevi C, Calvo M R, Oberg J C, Artiglia L, Agnoli S, Hirjibehedin C F, Chhowalla M, Saiz E. Activation energy paths for graphene nucleation and growth on $\mathrm{Cu}$. ACS Nano, 2012, 6(4): 3614-3623

87. Xing S, Wu W, Wang Y, Bao J, Pei S S. Kinetic study of graphene growth: temperature perspective on growth rate and film thickness by chemical vapor deposition. Chemical Physics Letters, 2013, 580: 62-66

88. Colombo L, Li X, Han B, Magnuson C, Cai W, Zhu Y, Ruoff R S. Growth kinetics and defects of CVD graphene on $\mathrm{Cu}$. ECS Transactions, 2010, 28: 109-114

89. Hao Y, Bharathi M S, Wang L, Liu Y, Chen H, Nie S, Wang X, Chou H, Tan C, Fallahazad B, Ramanarayan H, Magnuson C W, Tutuc E, Yakobson B I, McCarty K F, Zhang Y W, Kim P, Hone J, Colombo L, Ruoff R S. The role of surface oxygen in the growth of large single-crystal graphene on copper. Science, 2013, 342(6159): $720-723$

90. Shu H, Chen X, Tao X, Ding F. Edge structural stability and kinetics of graphene chemical vapor deposition growth. ACS Nano, 2012, 6(4): 3243-3250

91. Shibuta Y, Arifin R, Shimamura K, Oguri T, Shimojo F, Yamaguchi S. Low reactivity of methane on copper surface during graphene synthesis via CVD process: $\mathrm{Ab}$ initio molecular dynamics simulation. Chemical Physics Letters, 2014, 610-611: $33-38$

92. Liao M S, Au C T, Ng C F. Methane dissociation on Ni, Pd, Pt and $\mathrm{Cu}$ metal (111) surfaces - a theoretical comparative study. Chemical Physics Letters, 1997, 272(5-6): 445-452

93. Guéret C, Daroux M, Billaud F. Methane pyrolysis: thermodynamics. Chemical Engineering Science, 1997, 52(5): 815-827

94. Viñes F, Lykhach Y, Staudt T, Lorenz M P A, Papp C, Steinrück H P, Libuda J, Neyman K M, Görling A. Methane activation by platinum: critical role of edge and corner sites of metal nanoparticles. Chemistry (Weinheim an der Bergstrasse, Germany), 2010, 16(22): 6530-6539

95. Loginova E, Bartelt N C, Feibelman P J, McCarty K F. Evidence for graphene growth by $\mathrm{C}$ cluster attachment. New Journal of Physics, 2008, 10(9): 093026

96. Loginova E, Bartelt N C, Feibelman P J, McCarty K F. Factors influencing graphene growth on metal surfaces. New Journal of Physics, 2009, 11(6): 063046

97. López G A, Mittemeijer E J. The solubility of C in solid Cu. Scripta Materialia, 2004, 51(1): 1-5

98. Kim K S, Zhao Y, Jang H, Lee S Y, Kim J M, Kim K S, Ahn J H,
Kim P, Choi J Y, Hong B H. Large-scale pattern growth of graphene films for stretchable transparent electrodes. Nature, 2009, 457(7230): 706-710

99. Cai W, Piner R D, Zhu Y, Li X, Tan Z, Floresca H C, Yang C, Lu L, Kim M J, Ruoff R S. Synthesis of isotopically-labeled graphite films by cold-wall chemical vapor deposition and electronic properties of graphene obtained from such films. Nano Research, 2009, 2(11): 851-856

100. Wu P, Zhang W, Li Z, Yang J. Mechanisms of graphene growth on metal surfaces: theoretical perspectives. Small, 2014, 10(11): 2136-2150

101. Huang L, Chang Q H, Guo G L, Liu Y, Xie Y Q, Wang T, Ling B, Yang H F. Synthesis of high-quality graphene films on nickel foils by rapid thermal chemical vapor deposition. Carbon, 2012, 50(2): 551-556

102. Li H B, Page A J, Wang Y, Irle S, Morokuma K. Sub-surface nucleation of graphene precursors near a $\mathrm{Ni}(111)$ step-edge. Chemical Communications (Cambridge), 2012, 48(64): 79377939

103. Verma V P, Das S, Lahiri I, Choi W. Large-area graphene on polymer film for flexible and transparent anode in field emission device. Applied Physics Letters, 2010, 96(20): 203108

104. Kalita G, Matsushima M, Uchida H, Wakita K, Umeno M. Graphene constructed carbon thin films as transparent electrodes for solar cell applications. Journal of Materials Chemistry, 2010, 20 (43): 9713-9717

105. Nagai Y, Sugime H, Noda S. 1.5 Minute-synthesis of continuous graphene films by chemical vapor deposition on $\mathrm{Cu}$ foils rolled in three dimensions. Chemical Engineering Science, 2019, 201: 319324

106. Bae S, Kim H, Lee Y, Xu X, Park J S, Zheng Y, Balakrishnan J, Lei T, Kim H R, Song Y I, Kim Y J, Kim K S, Ozyilmaz B, Ahn J $\mathrm{H}$, Hong B H, Iijima S. Roll-to-roll production of 30-inch graphene films for transparent electrodes. Nature Nanotechnology, 2010, 5 (8): 574-578

107. Kim Y, Kim S, Lee W H, Kim H.Direct transfer of CVD-grown graphene onto eco-friendly cellulose film for highly sensitive gas sensor. Cellulose, 2020, 27: 1685-1693

108. Kim M, Shah A, Li C, Mustonen P, Susoma J, Manoocheri F, Riikonen J, Lipsanen H. Direct transfer of wafer-scale graphene films. 2D Materials, 2017, 4(3): 035004

109. Park I J, Kim T I, Yoon T, Kang S, Cho H, Cho N S, Lee J I, Kim T $\mathrm{S}$, Choi $\mathrm{S} \mathrm{Y}$. Flexible and transparent graphene electrode architecture with selective defect decoration for organic lightemitting diodes. Advanced Functional Materials, 2018, 28(10): 1704435

110. Liang X, Sperling B A, Calizo I, Cheng G, Hacker C A, Zhang Q, Obeng Y, Yan K, Peng H, Li Q, Zhu X, Yuan H, Walker A R, Liu Z, Peng L M, Richter C A. Toward clean and crackless transfer of graphene. ACS Nano, 2011, 5(11): 9144-9153

111. Li X, Zhu Y, Cai W, Borysiak M, Han B, Chen D, Piner R D, Colombo L, Ruoff R S. Transfer of large-area graphene films for high-performance transparent conductive electrodes. Nano Letters, 2009, 9(12): 4359-4363

112. Gammelgaard L, Caridad J M, Cagliani A, Mackenzie D M A, Petersen D H, Booth T J, Bøggild P. Graphene transport properties 
upon exposure to PMMA processing and heat treatments. 2D Materials, 2014, 1(3): 035005

113. Chan J, Venugopal A, Pirkle A, McDonnell S, Hinojos D, Magnuson C W, Ruoff R S, Colombo L, Wallace R M, Vogel E M. Reducing extrinsic performance-limiting factors in graphene grown by chemical vapor deposition. ACS Nano, 2012, 6(4): 3224-3229

114. Lin Y C, Lu C C, Yeh C H, Jin C, Suenaga K, Chiu P W. Graphene annealing: how clean can it be? Nano Letters, 2012, 12(1): 414419

115. Zhang Z, Du J, Zhang D, Sun H, Yin L, Ma L, Chen J, Ma D, Cheng H M, Ren W. Rosin-enabled ultraclean and damage-free transfer of graphene for large-area flexible organic light-emitting diodes. Nature Communications, 2017, 8(1): 14560

116. Lin Y C, Jin C, Lee J C, Jen S F, Suenaga K, Chiu P W. Clean transfer of graphene for isolation and suspension. ACS Nano, 2011, 5(3): 2362-2368

117. Kang M H, Prieto López L O, Chen B, Teo K, Williams J A, Milne W I, Cole M T. Mechanical robustness of graphene on flexible transparent substrates. ACS Applied Materials \& Interfaces, 2016, 8(34): 22506-22515

118. Song J, Kam F Y, Png R Q, Seah W L, Zhuo J M, Lim G K, Ho P K $\mathrm{H}$, Chua L L. A general method for transferring graphene onto soft surfaces. Nature Nanotechnology, 2013, 8(5): 356-362

119. Yoon J C, Thiyagarajan P, Ahn H J, Jang J H. A case study: effect of defects in CVD-grown graphene on graphene enhanced Raman spectroscopy. RSC Advances, 2015, 5(77): 62772-62777

120. Qin L, Kattel B, Kafle T R, Alamri M, Gong M, Panth M, Hou Y, Wu J, Chan W. Scalable graphene-on-organometal halide perovskite heterostructure fabricated by dry transfer. Advanced Materials Interfaces, 2019, 6(1): 1801419

121. Chandrashekar B N, Deng B, Smitha A S, Chen Y, Tan C, Zhang H, Peng H, Liu Z. Roll-to-roll green transfer of CVD graphene onto plastic for a transparent and flexible triboelectric nanogenerator. Advanced Materials, 2015, 27(35): 5210-5216

122. Marchena M, Wagner F, Arliguie T, Zhu B, Johnson B, Fernández M, Chen T L, Chang T, Lee R, Pruneri V, Mazumder P. Dry transfer of graphene to dielectrics and flexible substrates using polyimide as a transparent and stable intermediate layer. 2D Materials, 2018, 5(3): 035022

123. Shivayogimath A, Whelan P R, Mackenzie D M A, Luo B, Huang D, Luo D, Wang M, Gammelgaard L, Shi H, Ruoff R S, Bøggild P, Booth T J. Do-it-yourself transfer of large-area graphene using an office laminator and water. Chemistry of Materials, 2019, 31(7): $2328-2336$

124. Kang J, Hwang S, Kim J H, Kim M H, Ryu J, Seo S J, Hong B H, Kim M K, Choi J B. Efficient transfer of large-area graphene films onto rigid substrates by hot pressing. ACS Nano, 2012, 6(6): 5360 5365

125. Fechine G J M, Martin-Fernandez I, Yiapanis G, Bentini R, Kulkarni E S, Bof de Oliveira R V, Hu X, Yarovsky I, Castro Neto A H, Özyilmaz B. Direct dry transfer of chemical vapor deposition graphene to polymeric substrates. Carbon, 2015, 83: 224-231

126. Cherian C T, Giustiniano F, Martin-Fernandez I, Andersen H, Balakrishnan J, Özyilmaz B. 'Bubble-free' electrochemical delamination of CVD graphene films. Small, 2015, 11(2): 189-194
127. Wang Y, Zheng Y, Xu X, Dubuisson E, Bao Q, Lu J, Loh K P. Electrochemical delamination of CVD-grown graphene film: toward the recyclable use of copper catalyst. ACS Nano, 2011, 5 (12): 9927-9933

128. Pizzocchero F, Jessen B S, Whelan P R, Kostesha N, Lee S, Buron J D, Petrushina I, Larsen M B, Greenwood P, Cha W J, Teo K, Jepsen P U, Hone J, Bøggild P, Booth T J. Non-destructive electrochemical graphene transfer from reusable thin-film catalysts. Carbon, 2015, 85: 397-405

129. Zhan Z, Sun J, Liu L, Wang E, Cao Y, Lindvall N, Skoblin G, Yurgens A. Pore-free bubbling delamination of chemical vapor deposited graphene from copper foils. Journal of Materials Chemistry C, Materials for Optical and Electronic Devices, 2015, 3(33): 8634

130. Sun J, Chen Y, Cai X, Ma B, Chen Z, Priydarshi M K, Chen K, Gao T, Song X, Ji Q, Guo X, Zou D, Zhang Y, Liu Z. Direct lowtemperature synthesis of graphene on various glasses by plasmaenhanced chemical vapor deposition for versatile, cost-effective electrodes. Nano Research, 2015, 8(11): 3496-3504

131. Wei D, Peng L, Li M, Mao H, Niu T, Han C, Chen W, Wee A T S. Low temperature critical growth of high quality nitrogen doped graphene on dielectrics by plasma-enhanced chemical vapor deposition. ACS Nano, 2015, 9(1): 164-171

132. Zheng S, Zhong G, Wu X, D'Arsiè L, Robertson J. Metal-catalystfree growth of graphene on insulating substrates by ammoniaassisted microwave plasma-enhanced chemical vapor deposition. RSC Advances, 2017, 7: 33185-33193

133. Schmidt M E, Xu C, Cooke M, Mizuta H, Chong H M H. Metalfree plasma-enhanced chemical vapor deposition of large area nanocrystalline grapheme. Materials Research Express, 2014, 1(2): 025031

134. Wei N, Li Q, Cong S, Ci H, Song Y, Yang Q, Lu C, Li C, Zou G, Sun J, Zhang Y, Liu Z. Direct synthesis of flexible graphene glass with macroscopic uniformity enabled by copper-foam-assisted PECVD. Journal of Materials Chemistry A, Materials for Energy and Sustainability, 2019, 7(9): 4813-4822

135. Chen Z, Liu Y, Zhang W, Guo X, Yin L, Wang Y, Li L, Zhang Y, Wang Z, Zhang T. Growth of graphene/Ag nanowire/graphene sandwich films for transparent touch-sensitive electrodes. Materials Chemistry and Physics, 2019, 221: 78-88

136. Vishwakarma R, Zhu R, Abuelwafa A A, Mabuchi Y, Adhikari S, Ichimura S, Soga T, Umeno M. Direct synthesis of large-area graphene on insulating substrates at low temperature using microwave plasma CVD. ACS Omega, 2019, 4(6): 11263-11270

137. Park B J, Choi J S, Eom J H, Ha H, Kim H Y, Lee S, Shin H, Yoon $\mathrm{S}$ G. Defect-free graphene synthesized directly at $150^{\circ} \mathrm{C}$ via chemical vapor deposition with no transfer. ACS Nano, 2018, 12 (2): 2008-2016

138. Tran V D, Pammi S V N, Park B J, Han Y, Jeon C, Yoon S G. Transfer-free graphene electrodes for super-flexible and semitransparent perovskite solar cells fabricated under ambient air. Nano Energy, 2019, 65: 104018

139. Kwon K C, Kim B J, Lee J L, Kim S Y. Effect of anions in Au complexes on doping and degradation of graphene. Journal of Materials Chemistry C, Materials for Optical and Electronic Devices, 2013, 1(13): 2463-2469 
140. Jang C W, Kim J M, Kim J H, Shin D H, Kim S, Choi S H. Degradation reduction and stability enhancement of p-type graphene by $\mathrm{RhCl}_{3}$ doping. Journal of Alloys and Compounds, 2015, 621: 1-6

141. Bult J B, Crisp R, Perkins C L, Blackburn J L. Role of dopants in long-range charge carrier transport for p-type and n-type graphene transparent conducting thin films. ACS Nano, 2013, 7(8): 72517261

142. Liu H, Liu Y, Zhu D. Chemical doping of graphene. Journal of Materials Chemistry, 2011, 21(10): 3335-3345

143. Chae M S, Lee T H, Son K R, Kim Y W, Hwang K S, Kim T G. Electrically-doped CVD-graphene transparent electrodes: application in $365 \mathrm{~nm}$ light-emitting diodes. Nanoscale Horizons, 2019, 4 (3): $610-618$

144. Zhang X, Hsu A, Wang H, Song Y, Kong J, Dresselhaus M S, Palacios T. Impact of chlorine functionalization on high-mobility chemical vapor deposition grown graphene. ACS Nano, 2013, 7 (8): $7262-7270$

145. Gomez De Arco L, Zhang Y, Schlenker C W, Ryu K, Thompson M $\mathrm{E}$, Zhou C. Continuous, highly flexible, and transparent graphene films by chemical vapor deposition for organic photovoltaics. ACS Nano, 2010, 4(5): 2865-2873

146. Reina A, Jia X, Ho J, Nezich D, Son H, Bulovic V, Dresselhaus M S, Kong J. Large area, few-layer graphene films on arbitrary substrates by chemical vapor deposition. Nano Letters, 2009, 9(1): 30-35

147. Zan R, Altuntepe A. Nitrogen doping of graphene by CVD. Journal of Molecular Structure, 2020, 1199: 127026

148. Kim K K, Reina A, Shi Y, Park H, Li L J, Lee Y H, Kong J. Enhancing the conductivity of transparent graphene films via doping. Nanotechnology, 2010, 21(28): 285205

149. Bi H, Huang F, Liang J, Xie X, Jiang M. Transparent conductive graphene films synthesized by ambient pressure chemical vapor deposition used as the front electrode of CdTe solar cells. Advanced Materials, 2011, 23(28): 3202-3206

150. Guo C, Kong X, Ji H. Hot-roll-pressing mediated transfer of chemical vapor deposition graphene for transparent and flexible touch screen with low sheet-resistance. Journal of Nanoscience and Nanotechnology, 2018, 18(6): 4337-4342

151. Chang J H, Lin W H, Wang P C, Taur J I, Ku T A, Chen W T, Yan $\mathrm{S} \mathrm{J}, \mathrm{Wu} \mathrm{C}$ I. Solution-processed transparent blue organic lightemitting diodes with graphene as the top cathode. Scientific Reports, 2015, 5(1): 9693

152. Tongay S, Berke K, Lemaitre M, Nasrollahi Z, Tanner D B, Hebard A F, Appleton B R. Stable hole doping of graphene for low electrical resistance and high optical transparency. Nanotechnology, 2011, 22(42): 425701

153. Xu S C, Man B Y, Jiang S Z, Chen C S, Yang C, Liu M, Gao X G, Sun Z C, Zhang C. Flexible and transparent graphene-based loudspeakers. Applied Physics Letters, 2013, 102(15): 151902

154. Park H, Rowehl J A, Kim K K, Bulovic V, Kong J. Doped graphene electrodes for organic solar cells. Nanotechnology, 2010, 21(50): 505204

155. Galagan Y, Mescheloff A, Veenstra S C, Andriessen R, Katz E A. Reversible degradation in ITO-containing organic photovoltaics under concentrated sunlight. Physical Chemistry Chemical Phy- sics, 2015, 17(5): 3891-3897

156. Chochos C L, Spanos M, Katsouras A, Tatsi E, Drakopoulou S, Gregoriou V G, Avgeropoulos A. Current status, challenges and future outlook of high performance polymer semiconductors for organic photovoltaics modules. Progress in Polymer Science, 2019, 91: 51-79

157. Zhao J, Li Y, Yang G, Jiang K, Lin H, Ade H, Ma W, Yan H. Efficient organic solar cells processed from hydrocarbon solvents. Nature Energy, 2016, 1(2): 15027

158. Zhao W, Li S, Zhang S, Liu X, Hou J. Ternary polymer solar cells based on two acceptors and one donor for achieving $12.2 \%$ efficiency. Advanced Materials, 2017, 29(2): 1604059

159. Sun C, Pan F, Bin H, Zhang J, Xue L, Qiu B, Wei Z, Zhang Z G, Li $Y$. A low cost and high performance polymer donor material for polymer solar cells. Nature Communications, 2018, 9(1): 743

160. Nogay G, Sahli F, Werner J, Monnard R, Boccard M, Despeisse M, Haug F J, Jeangros Q, Ingenito A, Ballif C. 25.1\%-efficient monolithic perovskite/silicon tandem solar cell based on a $p$-type monocrystalline textured silicon wafer and high-temperature passivating contacts. ACS Energy Letters, 2019, 4(4): 844-845

161. La Notte L, Bianco G V, Palma A L, Di Carlo A, Bruno G, Reale A. Sprayed organic photovoltaic cells and mini-modules based on chemical vapor deposited graphene as transparent conductive electrode. Carbon, 2018, 129: 878-883

162. Park H, Chang S, Zhou X, Kong J, Palacios T, Gradečak S. Flexible graphene electrode-based organic photovoltaics with record-high efficiency. Nano Letters, 2014, 14(9): 5148-5154

163. Liu J, Durstock M, Dai L. Graphene oxide derivatives as hole- and electron-extraction layers for high-performance polymer solar cells. Energy \& Environmental Science, 2014, 7(4): 1297-1306

164. Capasso A, Salamandra L, Faggio G, Dikonimos T, Buonocore F, Morandi V, Ortolani L, Lisi N. Chemical vapor deposited graphene-based derivative as high-performance hole transport material for organic photovoltaics. ACS Applied Materials \& Interfaces, 2016, 8(36): 23844-23853

165. Mackenzie D M A, Buron J D, Whelan P R, Jessen B S, Silajdźić A, Pesquera A, Centeno A, Zurutuza A, Bøggild P, Petersen D H. Fabrication of CVD graphene-based devices via laser ablation for wafer-scale characterization. 2D Materials, 2015, 2(4): 045003

166. La Notte L, Villari E, Palma A L, Sacchetti A, Michela Giangregorio M, Bruno G, Di Carlo A, Bianco G V, Reale A. Laser-patterned functionalized CVD-graphene as highly transparent conductive electrodes for polymer solar cells. Nanoscale, 2017, 9(1): 62-69

167. Gomez De Arco L, Zhang Y, Schlenker C W, Ryu K, Thompson M E, Zhou C. Continuous, highly flexible, and transparent graphene films by chemical vapor deposition for organic photovoltaics. ACS Nano, 2010, 4(5): 2865-2873

168. Park H, Howden R M, Barr M C, Bulović V, Gleason K, Kong J. Organic solar cells with graphene electrodes and vapor printed poly (3,4-ethylenedioxythiophene) as the hole transporting layers. ACS Nano, 2012, 6(7): 6370-6377

169. Lee B H, Lee J H, Kahng Y H, Kim N, Kim Y J, Lee J, Lee T, Lee $\mathrm{K}$. Graphene-conducting polymer hybrid transparent electrodes for efficient organic optoelectronic devices. Advanced Functional Materials, 2014, 24(13): 1847-1856 
170. La Notte L, Cataldi P, Ceseracciu L, Bayer I S, Athanassiou A, Marras S, Villari E, Brunetti F, Reale A. Fully-sprayed flexible polymer solar cells with a cellulose-graphene electrode. Materials Today Energy, 2018, 7: 105-112

171. Rezaei B, Afshar-Taromi F, Ahmadi Z, Amiri Rigi S, Yousefi N. Enhancement of power conversion efficiency of bulk heterojunction polymer solar cells using core/shell, Au/graphene plasmonic nanostructure. Materials Chemistry and Physics, 2019, 228: 325335

172. Mahakul P C, Sa K, Das B, Subramaniam B V R S, Saha S, Moharana B, Raiguru J, Dash S, Mukherjee J, Mahanandia P. Preparation and characterization of PEDOT:PSS/reduced graphene oxide-carbon nanotubes hybrid composites for transparent electrode applications. Journal of Materials Science, 2017, 52(10): 5696-5707

173. Ricciardulli A G, Yang S, Wetzelaer G J A H, Feng X, Blom P W $M$. Hybrid silver nanowire and graphene-based solution-processed transparent electrode for organic optoelectronics. Advanced Functional Materials, 2018, 28(14): 1706010

174. Wang M, Yu H, Ma X, Yao Y, Wang L, Liu L, Cao K, Liu S, Dong C, Zhao B, Song C, Chen S, Huang W. Copper oxide-modified graphene anode and its application in organic photovoltaic cells. Optics Express, 2018, 26(18): A769-A776

175. Nan H, Han J, Luo Q, Yin X, Zhou Y, Yao Z, Zhao X, Li X, Lin H. Economically synthesized $\mathrm{NiCo}_{2} \mathrm{~S}_{4} /$ reduced graphene oxide composite as efficient counter electrode in dye-sensitized solar cell. Applied Surface Science, 2018, 437: 227-232

176. Sankar Ganesh R, Silambarasan K, Durgadevi E, Navaneethan M, Ponnusamy S, Kong C Y, Muthamizhchelvan C, Shimura Y, Hayakawa Y. Metal sulfide nanosheet-nitrogen-doped graphene hybrids as low-cost counter electrodes for dye-sensitized solar cells. Applied Surface Science, 2019, 480: 177-185

177. Silambarasan K, Archana J, Athithya S, Harish S, Sankar Ganesh R, Navaneethan M, Ponnusamy S, Muthamizhchelvan C, Hara K, Hayakawa Y. Hierarchical NiO@NiS@graphene nanocomposite as a sustainable counter electrode for Pt free dye-sensitized solar cell. Applied Surface Science, 2020, 501: 144010

178. Murugadoss V, Panneerselvam P, Yan C, Guo Z, Angaiah S. A simple one-step hydrothermal synthesis of cobalt nickel selenide/ graphene nanohybrid as an advanced platinum free counter electrode for dye sensitized solar cell. Electrochimica Acta, 2019, 312: 157-167

179. Rehman S, Noman M, Khan A D, Saboor A, Ahmad M S, Khan H U. Synthesis of polyvinyl acetate/graphene nanocomposite and its application as an electrolyte in dye sensitized solar cells. Optik (Stuttgart), 2020, 202: 163591

180. Chong S W, Lai C W, Juan J C, Leo B F. An investigation on surface modified $\mathrm{TiO}_{2}$ incorporated with graphene oxide for dyesensitized solar cell. Solar Energy, 2019, 191: 663-671

181. Wei L, Wang P, Yang Y, Zhan Z, Dong Y, Song W, Fan R. Enhanced performance of the dye-sensitized solar cells by the introduction of graphene oxide into the $\mathrm{TiO}_{2}$ photoanode. Inorganic Chemistry Frontiers, 2018, 5(1): 54-62

182. Sasikumar R, Chen T W, Chen S M, Rwei S P, Ramaraj S K. Developing the photovoltaic performance of dye-sensitized solar cells (DSSCs) using a $\mathrm{SnO}_{2}$-doped graphene oxide hybrid nanocomposite as a photo-anode. Optical Materials, 2018, 79: 345-352

183. Sadikin S N, Rahman M Y A, Umar A A, Aziz T H T. Improvement of dye-sensitized solar cell performance by utilizing graphene-coated $\mathrm{TiO}_{2}$ films photoanode. Superlattices and Microstructures, 2019, 128: 92-98

184. NREL. Best research-cell efficiencies (National Renewable Energy Laboratory: Golden, Colorado), 2019

185. Bag M, Renna L A, Adhikari R Y, Karak S, Liu F, Lahti P M, Russell T P, Tuominen M T, Venkataraman D. Kinetics of ion transport in perovskite active layers and its implications for active layer stability. Journal of the American Chemical Society, 2015, 137(40): 13130-13137

186. Bastos J P, Paetzold U W, Gehlhaar R, Qiu W, Cheyns D, Surana S, Spampinato V, Aernouts T, Poortmans J. Light-induced degradation of perovskite solar cells: the influence of 4-tert-butyl pyridine and gold. Advanced Energy Materials, 2018, 8(23): 1800554

187. Raga S R, Jung M C, Lee M V, Leyden M R, Kato Y, Qi Y. Influence of air annealing on high efficiency planar structure perovskite solar cells. Chemistry of Materials, 2015, 27(5): 15971603

188. Christians J A, Miranda Herrera P A, Kamat P V. Transformation of the excited state and photovoltaic efficiency of $\mathrm{CH}_{3} \mathrm{NH}_{3} \mathrm{PbI}_{3}$ perovskite upon controlled exposure to humidified air. Journal of the American Chemical Society, 2015, 137(4): 1530-1538

189. Domanski K, Correa-Baena J P, Mine N, Nazeeruddin M K, Abate A, Saliba M, Tress W, Hagfeldt A, Grätzel M. Not all that glitters is gold: metal-migration-induced degradation in perovskite solar cells. ACS Nano, 2016, 10(6): 6306-6314

190. Guerrero A, You J, Aranda C, Kang Y S, Garcia-Belmonte G, Zhou H, Bisquert J, Yang Y. Interfacial degradation of planar lead halide perovskite solar cells. ACS Nano, 2016, 10(1): 218-224

191. Wang R, Mujahid M, Duan Y, Wang Z, Xue J, Yang Y. A review of perovskites solar cell stability. Advanced Functional Materials, 2019, 29(47): 1808843

192. Jeong G, Koo D, Seo J, Jung S, Choi Y, Lee J, Park H. Suppressed interdiffusion and degradation in flexible and transparent metal electrode-based perovskite solar cells with a graphene interlayer. Nano Letters, 2020, 20(5): 3718-3727

193. Tavakoli M M, Tavakoli R, Yadav P, Kong J. A graphene/ZnO electron transfer layer together with perovskite passivation enables highly efficient and stable perovskite solar cells. Journal of Materials Chemistry A, Materials for Energy and Sustainability, 2019, 7(2): 679-686

194. Kim J M, Jang C W, Kim J H, Kim S, Choi S H. Use of $\mathrm{AuCl}_{3^{-}}$ doped graphene as a protecting layer for enhancing the stabilities of inverted perovskite solar cells. Applied Surface Science, 2018, 455: 1131-1136

195. Jokar E, Huang Z Y, Narra S, Wang C Y, Kattoor V, Chung C C, Diau E W G. Anomalous charge-extraction behavior for grapheneoxide (GO) and reduced graphene-oxide (rGO) films as efficient pcontact layers for high-performance perovskite solar cells. Advanced Energy Materials, 2018, 8(3): 1701640

196. Cogal S, Calio L, Celik Cogal G, Salado M, Kazim S, Oksuz L, Ahmad S, Uygun Oksuz A. RF plasma-enhanced graphene- 
polymer composites as hole transport materials for perovskite solar cells. Polymer Bulletin, 2018, 75(10): 4531-4545

197. Nouri E, Mohammadi M R, Lianos P. Improving the stability of inverted perovskite solar cells under ambient conditions with graphene-based inorganic charge transporting layers. Carbon, 2018, 126: 208-214

198. Zhao X, Tao L, Li H, Huang W, Sun P, Liu J, Liu S, Sun Q, Cui Z, Sun L, Shen Y, Yang Y, Wang M. Efficient planar perovskite solar cells with improved fill factor via interface engineering with graphene. Nano Letters, 2018, 18(4): 2442-2449

199. O'Keeffe P, Catone D, Paladini A, Toschi F, Turchini S, Avaldi L, Martelli F, Agresti A, Pescetelli S, Del Rio Castillo A E, Bonaccorso F, Di Carlo A. Graphene-induced improvements of perovskite solar cell stability: effects on hot-carriers. Nano Letters, 2019, 19(2): 684-691

200. Yoon J, Sung H, Lee G, Cho W, Ahn N, Jung H S, Choi M. Superflexible, high-efficiency perovskite solar cells utilizing graphene electrodes: towards future foldable power sources. Energy \& Environmental Science, 2017, 10(1): 337-345

201. Heo J H, Shin D H, Song D H, Kim D H, Lee S J, Im S H. Superflexible bis(trifluoromethanesulfonyl)-amide doped graphene transparent conductive electrodes for photo-stable perovskite solar cells. Journal of Materials Chemistry A, Materials for Energy and Sustainability, 2018, 6(18): 8251-8258

202. Zhang C, Wang S, Zhang H, Feng Y, Tian W, Yan Y, Bian J, Wang Y, Jin S, Zakeeruddin S M, Grätzel M, Shi Y. Efficient stable graphene-based perovskite solar cells with high flexibility in device assembling via modular architecture design. Energy \& Environmental Science, 2019, 12(12): 3585-3594

203. Sung H, Ahn N, Jang M S, Lee J K, Yoon H, Park N G, Choi M. Transparent conductive oxide-free graphene-based perovskite solar cells with over 17\% efficiency. Advanced Energy Materials, 2016, 6(3): 1501873

204. Fu W, Jiang L, van Geest E P, Lima L M C, Schneider G F. Sensing at the surface of graphene field-effect transistors. Advanced Materials, 2017, 29(6): 1603610

205. Afsahi S, Lerner M B, Goldstein J M, Lee J, Tang X, Bagarozzi D A Jr, Pan D, Locascio L, Walker A, Barron F, Goldsmith B R. Novel graphene-based biosensor for early detection of Zika virus infection. Biosensors \& Bioelectronics, 2018, 100: 85-88

206. Chen S, Sun Y, Xia Y, Lv K, Man B, Yang C. Donor effect dominated molybdenum disulfide/graphene nanostructure-based field-effect transistor for ultrasensitive DNA detection. Biosensors \& Bioelectronics, 2020, 156: 112128

207. Hwang M T, Heiranian M, Kim Y, You S, Leem J, Taqieddin A, Faramarzi V, Jing Y, Park I, van der Zande A M, Nam S, Aluru N $\mathrm{R}$, Bashir R. Ultrasensitive detection of nucleic acids using deformed graphene channel field effect biosensors. Nature Communications, 2020, 11(1): 1543

208. Kim S, Xing L, Islam A E, Hsiao M S, Ngo Y, Pavlyuk O M, Martineau R L, Hampton C M, Crasto C, Slocik J, Kadakia M P, Hagen J A, Kelley-Loughnane N, Naik R R, Drummy L F. In operando observation of neuropeptide capture and release on graphene field-effect transistor biosensors with picomolar sensitivity. ACS Applied Materials \& Interfaces, 2019, 11(15): 1392713934
209. Seo G, Lee G, Kim M J, Baek S H, Choi M, Ku K B, Lee C S, Jun S, Park D, Kim H G, Kim S J, Lee J O, Kim B T, Park E C, Kim S I. Rapid detection of COVID-19 causative virus (SARS-CoV-2) in human nasopharyngeal swab specimens using field-effect transistor-based biosensor. ACS Nano, 2020, 14(4): 5135-5142

210. Loan P T K, Wu D, Ye C, Li X, Tra V T, Wei Q, Fu L, Yu A, Li L J, Lin C T. Hall effect biosensors with ultraclean graphene film for improved sensitivity of label-free DNA detection. Biosensors \& Bioelectronics, 2018, 99: 85-91

211. Zhan H, Cervenka J, Prawer S, Garrett D J. Molecular detection by liquid gated Hall effect measurements of graphene. Nanoscale, 2018, 10(3): 930-935

212. Li N, Tang T, Li J, Luo L, Li C, Shen J, Yao J. Highly sensitive biosensor with graphene- $\mathrm{MoS}_{2}$ heterostructure based on photonic spin Hall effect. Journal of Magnetism and Magnetic Materials, 2019, 484: 445-450

213. Zhou X, Sheng L, Ling X. Photonic spin Hall effect enabled refractive index sensor using weak measurements. Scientific Reports, 2018, 8(1): 1221

214. Zhao Z, Yang H, Zhao W, Deng S, Zhang K, Deng R, He Q, Gao $\mathrm{H}$, Li J. Graphene-nucleic acid biointerface-engineered biosensors with tunable dynamic range. Journal of Materials Chemistry B, Materials for Biology and Medicine, 2020, 8(16): 3623-3630

215. Xie K X, Cao S H, Wang Z C, Weng Y H, Huo S X, Zhai Y Y, Chen M, Pan X H, Li Y Q. Graphene oxide-assisted surface plasmon coupled emission for amplified fluorescence immunoassay. Sensors and Actuators B, Chemical, 2017, 253: 804-808

216. Sun L, Zhang Y, Wang Y, Yang Y, Zhang C, Weng X, Zhu S, Yuan $\mathrm{X}$. Real-time subcellular imaging based on graphene biosensors. Nanoscale, 2018, 10(4): 1759-1765

217. Xu Y, Zhuang R, Zhang Z, Yi R, Guo X, Qi Z. Single-layer graphene-based surface plasmon resonance biosensors for immunization study. In: Proceedings of the 8th Applied Optics and Photonics China (AOPC 2019), Optical Spectroscopy Imaging, 2019, 11337

218. Rahman M S, Anower M S, Hasan M R, Hossain M B, Haque M I. Design and numerical analysis of highly sensitive $\mathrm{Au}-\mathrm{MoS}_{2}$ graphene based hybrid surface plasmon resonance biosensor. Optics Communications, 2017, 396: 36-43

219. Gopalan K K, Paulillo B, Mackenzie D M A, Rodrigo D, Bareza N, Whelan P R, Shivayogimath A, Pruneri V. Scalable and tunable periodic graphene nanohole arrays for mid-infrared plasmonics. Nano Letters, 2018, 18(9): 5913-5918

220. Siegel P H. Terahertz technology in biology and medicine. IEEE Transactions on Microwave Theory and Techniques, 2004, 52(10): $2438-2447$

221. Jepsen P U, Cooke D G, Koch M. Terahertz spectroscopy and imaging-modern techniques and applications. Laser \& Photonics Reviews, 2011, 5(1): 124-166

222. Sengupta K. Integrated circuits for terahertz communication beyond $100 \mathrm{GHz}$ : are we there yet? In: Proceedings of IEEE International Conference on Communications, Workshop ICC Workshop, 2019

223. Ajito K, Ueno Y. THz chemical imaging for biological applications. IEEE Transactions on Terahertz Science and Technology, 2011, 1(1): 293-300 
224. Auton G, But D B, Zhang J, Hill E, Coquillat D, Consejo C, Nouvel P, Knap W, Varani L, Teppe F, Torres J, Song A. Terahertz detection and imaging using graphene ballistic rectifiers. Nano Letters, 2017, 17(11): 7015-7020

225. Yang X, Vorobiev A, Generalov A, Andersson M A, Stake J. A flexible graphene terahertz detector. Applied Physics Letters, 2017, 111(2): 021102

226. Yang X X, Sun J D, Qin H, Lv L, Su L N, Yan B, Li X X, Zhang Z $\mathrm{P}$, Fang J Y. Room-temperature terahertz detection based on CVD graphene transistor. Chinese Physics B, 2015, 24(4): 047206

227. Valmorra F, Scalari G, Maissen C, Fu W, Schönenberger C, Choi J W, Park H G, Beck M, Faist J. Low-bias active control of terahertz waves by coupling large-area CVD graphene to a terahertz metamaterial. Nano Letters, 2013, 13(7): 3193-3198

228. Generalov A A, Andersson M A, Yang X, Vorobiev A, Stake J A. 400-GHz graphene FET detector. IEEE Transactions on Terahertz Science and Technology, 2017, 7(5): 614-616

229. Kakenov N, Ergoktas M S, Balci O, Kocabas C. Graphene based terahertz phase modulators. 2D Materials, 2018, 5(3): 035018

230. Shin J W, Cho H, Lee J, Moon J, Han J H, Kim K, Cho S, Lee J I, Kwon B H, Cho D H, Lee K M, Suemitsu M, Cho N S. Overcoming the efficiency limit of organic light-emitting diodes using ultra-thin and transparent graphene electrodes. Optics Express, 2018, 26(2): 617-626

231. Shin J W, Han J H, Cho H, Moon J, Kwon B H, Cho S, Yoon T, Kim T S, Suemitsu M, Lee J I, Cho N S. Display process compatible accurate graphene patterning for OLED applications. 2D Materials, 2017, 5(1): 014003

232. Lee J, Han T H, Park M H, Jung D Y, Seo J, Seo H K, Cho H, Kim E, Chung J, Choi S Y, Kim T S, Lee T W, Yoo S. Synergetic electrode architecture for efficient graphene-based flexible organic light-emitting diodes. Nature Communications, 2016, 7(1): 11791

233. Kwon O E, Shin J W, Oh H, Kang C, Cho H, Kwon B H, Byun C W, Yang J H, Lee K M, Han J H, Sung Cho N, Hyuk Yoon J, Jin Chae S, Sung Park J, Lee H, Hwang C S, Moon J, Lee J I. A prototype active-matrix OLED using graphene anode for flexible display application. Journal of Information Display, 2020, 21(1): $49-56$

234. Zhang Z, Du J, Zhang D, Sun H, Yin L, Ma L, Chen J, Ma D, Cheng H M, Ren W. Rosin-enabled ultraclean and damage-free transfer of graphene for large-area flexible organic light-emitting diodes. Nature Communications, 2017, 8(1): 14560

235. Torres Alonso E, Karkera G, Jones G F, Craciun M F, Russo S. Homogeneously bright, flexible, and foldable lighting devices with functionalized graphene electrodes. ACS Applied Materials \& Interfaces, 2016, 8(26): 16541-16545

236. Wang Z G, Chen Y F, Li P J, Hao X, Liu J B, Huang R, Li Y R. Flexible graphene-based electroluminescent devices. ACS Nano, 2011, 5(9): 7149-7154

237. Shin H, Sharma B K, Lee S W, Lee J B, Choi M, Hu L, Park C, Choi J H, Kim T W, Ahn J H. Stretchable electroluminescent display enabled by graphene-based hybrid electrode. ACS Applied Materials \& Interfaces, 2019, 11(15): 14222-14228

238. Chandran A, Joshi T, Sharma I, Subhedar K M, Mehta D S, Biradar A M. Monolayer graphene electrodes as alignment layer for ferroelectric liquid crystal devices. Journal of Molecular Liquids,
2019, 279: 294-298

239. Hu T, Wang H, Shao Y, Zhang X, Liu G, Li M, Chen H, Lee Y. 663: a high reliability PEDOT:PSS/graphene transparent electrode for liquid crystal displays. SID Symposium Digest of Technical Papers, 2017, 48(1): 972-975

240. Petrov S, Marinova V, Lin S H, Chang C M, Lin Y H, Hsu K Y. Large scale liquid crystal device with graphene-based electrodes. Optical Data Processing and Storage, 2017, 3(1): 114-118

241. Mustapha N, Fekkai Z, Ibnaouf K H. Improved performance of organic light-emitting diodes based on oligomer thin films with graphene. Journal of Electronic Materials, 2020, 49(3): 2203-2210

242. Fu Y, Sun J, Du Z, Guo W, Yan C, Xiong F, Wang L, Dong Y, Xu C, Deng J, Guo T, Yan Q F. Monolithic integrated device of GaN micro-LED with graphene transparent electrode and graphene active-matrix driving transistor. Materials (Basel), 2019, 12(3): 428

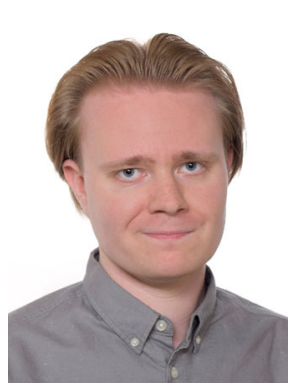

Petri Mustonen got his B.Sc. and M.Sc. degrees from Aalto University, Finland and continued his work there as a doctoral candidate in Department of Electronics and Nanoengineering. He has been working in the field of 2D materials since 2014 and currently his focus is on chemical vapor deposition and characterization of graphene and other novel 2D materials. In general, his interests lie in bridging the gap between laboratory- and industrial-scale manufacturing of 2D materials.

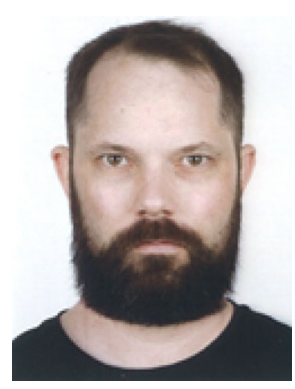

David M. A. Mackenzie graduated from University of Canterbury, New Zealand in 2010 with a Ph.D. degree in Physics based on nanoscale cluster devices. He joined the Micro and Nanotechnology Department at Technical University of Denmark, Denmark in 2012 as a Postdoctoral Researcher where he worked on 2D material devices including nanopatterned transistors and nanopatterned gas sensors. He moved to Aalto University in Finland in 2018 and is currently involved with growth and characterization of novel 2D materials.

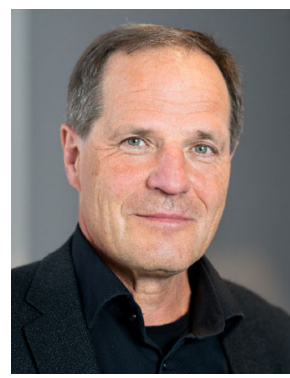

Prof. Harri Lipsanen received his Ph.D. degree from Helsinki University of Technology, Finland in 1994 and is Full Professor in Department of Electronics and Nanoengineering, Aalto University, Finland. He studies nanomaterials and nanofabrication for various applications in photonics and nanoelectronics. His current research focus on materials includes graphene and other 2D materials, semiconductor nanowires and their heterostructures. The nanofabrication activities extend over many methods such as atomic layer deposition, metalorganic vapor phase epitaxy, electron beam lithography, and self-assembly. Prof. Lipsanen has published over 300 peer-reviewed articles. 